\title{
INKA2, a novel p53 target that interacts with the serine/threonine kinase PAK4
}

\author{
YU-YU LIU ${ }^{1}$, CHIZU TANIKAWA ${ }^{2}$, KOJI UEDA $^{3}$ and KOICHI MATSUDA ${ }^{1,2}$ \\ ${ }^{1}$ Laboratory of Clinical Genome Sequencing, Department of Computational Biology and Medical Sciences, \\ Graduate School of Frontier Sciences, and ${ }^{2}$ Laboratory of Molecular Medicine, Human Genome Center, \\ Institute of Medical Science, The University of Tokyo 108-8639, Tokyo; \\ ${ }^{3}$ Project for Realization of Personalized Cancer Medicine, Cancer Precision Medicine Center, \\ Japanese Foundation for Cancer Research, Tokyo 135-8550, Japan
}

Received December 12, 2018; Accepted March 21, 2019

DOI: $10.3892 /$ ijo.2019.4786

\begin{abstract}
The p53 protein is a tumour suppressor and transcription factor that regulates the expression of target genes involved in numerous stress responses systems. In this study, we designed a screening strategy using DNA damage-induced mouse and human transcriptome data to identify novel downstream targets of p53. Our method selected genes with an induced expression in multiple organs of X-ray-irradiated $p 53$ wild-type mice. The expression of inka box actin regulator 2 gene, known as Inka2, was upregulated in 12 organs when p53 expression was induced. Similarly, INKA2 was induced in a p53-dependent manner at both the mRNA and protein level in human cells treated with adriamycin. Reporter assays confirmed that p53 directly regulated INKA2 through an intronic binding site. The overexpression of INKA2 produced a slight decrease in cancer cell growth in the colony formation assay. Moreover, the analysis of The Cancer Genome Atlas (TCGA) data revealed a decreased INKA2 expression in tumour samples carrying $p 53$ mutations compared with $p 53$ wild-type samples. In addition, significantly higher levels of DNA methylation were observed in the INKA2 promoter in tumour samples, concordant with the reduced INKA2 expression in tumour tissues. These results demonstrate the potential of INKA2 as a cancer cell growth inhibitor. Furthermore, INKA2 protein interacts with the serine/threonine-protein kinase, p21 (RAC1) activated kinase (PAK)4, which phosphorylates $\beta$-catenin to prevent ubiquitin-proteasomal degradation. As $\beta$-catenin was downregulated in a stable INKA2-expressing cell line, the findings of this study suggest that INKA2 is a novel, direct
\end{abstract}

Correspondence to: Professor Koichi Matsuda, Laboratory of Clinical Genome Sequencing, Department of Computational Biology and Medical Sciences, Graduate School of Frontier Sciences, The University of Tokyo, 4-6-1 Shirokanedai, Minato-ku, Tokyo 108-8639, Japan

E-mail: kmatsuda@edu.k.u-tokyo.ac.jp

Key words: inka box actin regulator 2, p53, p21 (RAC1) activated kinase 4 , cancer cell growth inhibitor downstream target of p53 that potentially decreases cell growth by inhibiting the PAK4- $\beta$-catenin pathway.

\section{Introduction}

The p53 protein is essential for the cellular stress response system and is activated by numerous stress signals. The protein functions as a transcription factor that regulates the expression of a large number of target genes involved in DNA repair, apoptosis, cell cycle arrest, differentiation and other responses (1). The cyclin-dependent kinase inhibitor 1 (also known as CDKN1A) represents one of the major targets of p53. The gene is known for its essential role in p53-mediated cell cycle arrest in response to DNA damage (2-4). The activation of p53 followed by the induction of CDKN1A has been observed in various DNA damage treatments in mouse and human cells $(3,5-7)$. Likewise, numerous downstream targets have been identified in the p53 signalling pathway. For example, the BCL2 associated X protein (BAX), NOXA and p53-regulated apoptosis-inducing protein 1 (P53AIP1) proteins have been shown to play a role in cell apoptosis (1), and proliferating cell nuclear antigen (PCNA) (8) and $O$-6-methylguanine-DNA methyltransferase (MGMT) (9) are involved in DNA repair. Among the types of human cancer, the p53 tumour suppressor gene is the most frequently mutated gene. The oncogenic point mutations within the $p 53$ gene are mainly located in the DNA-binding domain (10), revealing the importance of the function of the transcription factor.

Although a large number of p53 target genes have been reported, none of the genes have been identified using a strategy covering multiple organs and various species, at least to the best of our knowledge. In this study, we screened p53 target genes from mouse transcriptome data obtained from 24 tissues in p53 wild-type or knockout mice treated with or without whole-body X-ray irradiation. From the same data, our previous study revealed 3,551 upregulated genes and 2,576 downregulated genes induced by p53 in all mouse tissues. A portion of the identified p53-dependent genes were involved in carcinogenesis and DNA damage responsive signalling pathways (11). A large number of the identified p53-repressed genes were regulated indirectly by p53 via a 
CDKN1A-mediated system (12). Subsequently, our screening strategy considered only upregulated genes to exclude targets that are regulated indirectly by $\mathrm{p} 53$.

\section{Materials and methods}

Screening materials. All mice were maintained in temperature-controlled, air-conditioned, and specific pathogen-free conditions on a 12-h light/dark cycle, and handled in accordance with the Guidelines for Animal Experiments of the Institute of Medical Science (University of Tokyo, Tokyo, Japan). Mice were given access to a standard laboratory diet and water. The animal experiment was approved by the institutional review board of the University of Tokyo (A13-03). $p 53^{-/}$mice were provided from the RIKEN BioResource Center (Ibaragi, Japan). Mice were treated with $10 \mathrm{~Gy}$ of $\mathrm{X}$-ray irradiation, and tissues were subjected to RNA-seq as described in our previous studies $(11,12)$. Briefly, $p 53^{+/+}$and $p 53^{-/}$mice were X-ray-irradiated using the MBR-1520R-3 system (Hitachi, Tokyo, Japan), and 24 tissues were collected from each mouse at the 24-h time-point following irradiation (bladder, bone marrow, cerebrum, colon, epididymis, esophagus, eyeball, heart, kidney, liver, lung, muscle, seminal vesicle, small intestine, spleen, stomach, testis, thymus and tongue: male, 6 weeks old, $\mathrm{n}=3$ each; skull, cartilage/knee: male, 1 week old, $n=3$ each; uterus: female, 10 weeks old, $\mathrm{n}=3$ each; mammary gland and ovary: female, 10 weeks old, $\mathrm{n}=2$ each). Total RNA was recovered from the homogenised tissues using the RNeasy Plus Universal Mini kit or RNeasy Plus Mini kit (Qiagen, Valencia, CA, USA). The samples were selected by the evaluation of the RNA quality and quantity using the Bioanalyzer (Agilent Technologies, Santa Clara, CA, USA) and Nanodrop (Thermo Fisher Scientific, Waltham, MA, USA). High-quality RNA was subjected to polyA+ selection and chemical fragmentation, and a 100-200-base RNA fraction was used to construct complementary DNA libraries according to Illumina's protocol. RNA-seq was performed with HiSeq 2500 using a standard paired-end 101-bp protocol. The raw data for the RNA-seq are available on the DNA Data Bank of Japan (DDBJ) database (http://www.ddbj.nig.ac.jp/index-e. html) under the accession no. DRA005768, and bioproject accession no. PRJDB5738. The cDNA microarray of MCF10A and HCT116 cells was performed using methods described in previous studies (12-14). Briefly, the MCF10A and HCT116 $p 53^{+/+}$or $p 53^{-/}$cells were treated with adriamycin (ADR) for $2 \mathrm{~h}$ and cultured with fresh medium until harvest. The concentration of ADR applied was 0.5 and $2 \mu \mathrm{g} / \mathrm{ml}$ for the MCF10A and HCT116 cells, respectively. Total RNA was isolated from the cells using the RNeasy Plus Universal Mini kit (Qiagen) at 0, 12, 24 and $48 \mathrm{~h}$ following ADR treatment. Each RNA sample was labeled and hybridised to array slides. Gene expression analysis was performed using a SurePrint G3 Human GE 8x60K microarray (Agilent Technologies) according to the manufacturer's instructions. The microarray data are available from the NCBI GEO database. The accession no. is GSE98727 for the MCF10A cells and GSE125787 for the HCT116 cells.

Screening strategy. In the mouse transcriptome data, genes with a low expression were defined as those with a maximum expression in all groups (W, $p 53^{+/+}$; WX, irradiated $p 53^{+/+}$; $\mathrm{K}, p 53^{-/-} ; \mathrm{KX}$, irradiated $p 53^{-/-}$) among all 24 tissues inferior to 1 fragment per kilobase million (FPKM), and were excluded from the screening. Subsequently, the gene expression levels in mice in the WX group ( $\mathrm{n}=2$ for the mammary gland, ovary and uterus; $\mathrm{n}=3$ for other organs) were compared to the gene expression levels in mice in the $\mathrm{W}, \mathrm{K}$ and $\mathrm{KX}$ groups (same ' $n$ ' as WX for each group, resulting in a total of $n=6$ for the mammary gland, ovary and uterus; $n=9$ for other organs). The expression fold change was calculated with the following formula: Median expression in (WX)/maximum of median expression in $(\mathrm{W}),(\mathrm{K})$ or $(\mathrm{KX})$. Genes with a significant expression fold change $>3$-fold were extracted. One-way ANOVA with a Dunnett's post hoc test was performed to calculate the P-values between the WX group and each of the other groups (W, K or KX). In the final step of the screening process, genes with a significantly upregulated expression in the WX group in no less than 10 of 24 tissues were selected. In the human cell transcriptome data, the expression of ADR-treated $p 53^{+/+}$cells $(\mathrm{n}=3)$ was compared to the group gathering $p 53^{-/}$cells and untreated $p 53^{+/+}$cells $(\mathrm{n}=5)$. The expression fold change was calculated by the following formula: Median expression of $p 53^{+/+}$cells (ADR $12 \mathrm{~h}$ ), (ADR $24 \mathrm{~h}$ ) and (ADR $48 \mathrm{~h}$ )/maximum expression in $p 53^{-/}$cells $(0 \mathrm{~h}),($ ADR $12 \mathrm{~h}),($ ADR $24 \mathrm{~h})$, (ADR $48 \mathrm{~h}$ ), and $p 53^{+/+}$cells $(0 \mathrm{~h})$. Genes with an upregulated expression in the ADR-treated $p 53^{+/+}$cells were defined by a significant expression fold change $>1.5$-fold. The two-tailed Student's t-test was used to calculate the P-values.

Cell lines and treatments. HCT116 (colorectal adenocarcinoma), U2OS (osteosarcoma) and H1299 (lung adenocarcinoma) cells were purchased from the American Type Cell Collection (Manassas, VA, USA) (cat. nos. CCL-247, HTB-96 and CRL-5803, respectively). The HCT116 $p 53^{+/+}$and HCT116 $p 53^{-/-}$cells were gifts from Dr B. Vogelstein (Johns Hopkins University, Baltimore, MD, USA). MCF10A (breast epithelial cells) $p 53^{+/+}$and $p 53^{-/-}$cell lines were purchased from Sigma-Aldrich (St. Louis, MO, USA). HBC4 (breast cancer) cells were a gift from Dr T. Yamori (The Cancer Institute of Japanese Foundation for Cancer Research, Tokyo, Japan). 293T cells (subclone of 293 cells expressing SV40 large T-antigen) were purchased from the RIKEN Cell Bank (Ibaraki, Japan). All cells were cultured in a $37^{\circ} \mathrm{C}$ incubator with a $5 \% \mathrm{CO}_{2}$ atmosphere. The siRNA oligonucleotides were ordered from Sigma-Aldrich and transfected into the cells using Lipofectamine RNAiMAX (Thermo Fisher Scientific) at the seeding step. The sequences are listed in Table SI. Gene overexpression experiments were performed by transfecting plasmids into cells with FuGENE6 (Promega, Madison, WI, USA). The cells were treated with ADR for $2 \mathrm{~h}$ at the 24-h timepoint after seeding to induce DNA damage and $\mathrm{p} 53$ expression. The U2OS and HBC4 cells were treated with $2 \mu \mathrm{g} / \mathrm{ml}$ of ADR. Total RNA was extracted or whole cell lysates were prepared $48 \mathrm{~h}$ following treatment for reverse transcription-quantitative PCR (RT-qPCR) or western blot analysis, respectively. Cell lines stably expressing INKA2 were generated by transfecting the HCT116 cells with pLenti6.3/TO/V5-DEST/INKA2-CDS constructed as previously described (14). Briefly, the full-length INKA2 cDNA fragment was integrated into the destination vector pLenti6.3/TO/V5-DEST using the Gateway LR 
Clonase II enzyme mix, all provided by Invitrogen/Thermo Fisher Scientific. The plasmid contains the selectable marker G418 and the Blasticidin S-resistance gene. Transfected cells were selected by the addition of Blasticidin and Geneticin ${ }^{\circledR}$ to the culture medium for 3 weeks.

RNA extraction and $R T-q P C R$. Following the treatments, total RNA was extracted from the cells using an RNeasy Plus Mini kit (Qiagen) according to the manufacturer's instructions. SuperScript III reverse transcriptase (Invitrogen/Thermo Fisher Scientific) was used to synthesise cDNA from the collected RNA samples. The resulting cDNA was employed as template for qPCR using SYBR-Green Master Mix and a Light Cycler 480 machine (Roche Applied Science, Basel, Switzerland). The expression level of the housekeeping gene, GAPDH, was used for normalization. The primer sequences are presented in Table SI.

Immunocytochemistry. The cells were plated in 24-well culture plates with glass coverslips on the bottom. Cells were transfected with the siRNAs at the same time as the seeding step. For drug treatments, $2 \mu \mathrm{g} / \mathrm{ml}$ of ADR or $1 \mu \mathrm{g} / \mathrm{ml}$ of doxycycline (Dox) were added at $24 \mathrm{~h}$ after plating. The ADR treatment lasted for $2 \mathrm{~h}$ and Dox remained in the medium until the cells were harvested. At $48 \mathrm{~h}$ after the addition of the drugs, the cells were fixed with $4 \%$ paraformaldehyde and permeabilised with $0.2 \%$ Triton $\mathrm{X}-100$ in PBS. A 3\% BSA solution was applied in the blocking step, and the cells were incubated with antibodies in the same blocking solution. The antibodies were diluted and used for incubation according to each manufacturer's protocol. Details for the antibodies used in the present study are presented in Table SII. Finally, the samples were mounted in Vectashield Mounting Medium with DAPI (Vector Laboratories, Burlingame, CA, USA) and kept in $4^{\circ} \mathrm{C}$ until photography. A confocal microscope (Olympus FluoView FV1000) was used to visualise the mounted coverslips.

Binding site analysis. ChIP data targeting human and mouse p53 proteins were downloaded from the ReMap 2018 (15) and ChIPBase (16) databases, respectively. Overlapping peaks were merged into a single peak for analysis. The DNA sequence from -10 to $+10 \mathrm{~kb}$ of the INKA2 gene was submitted to the binding motif scanning tool in the JASPAR database (17) to identify the candidate p53 binding sites. Binding scores were calculated and provided by the database. p53 binding sites reported for human (18) or mouse (19) CDKN1A were subjected to JASPAR binding site scanning analysis to confirm the authenticity of the prediction (Table SIII). Likewise, the p53 binding motif used from JASPAR (MA0106.3) was compared with a refined consensus p53 binding motif of high prediction accuracy (18). Large resemblance was observed between the two models, and both were based on the known p53 binding motif composed of two repeated palindromic motif RRRCWWGYYY (Fig. S1).

Protein extraction and western blot analysis. Whole-cell lysates were prepared from adherent cells with RIPA buffer (Thermo Fisher Scientific) containing $1 \mathrm{mM}$ PMSF, 0.1 mM DTT and 0.1\% Protease Inhibitor Cocktail Set III (Calbiochem, La Jolla,
CA, USA). Cell lysates were sonicated 15 times for $30 \mathrm{sec}$ each using a Bioruptor UCD-200 (Cosmo Bio, Tokyo, Japan). The protein concentrations of the resulting lysates were measured using the $\mathrm{BCA}^{\mathrm{TM}}$ protein assay (Thermo Fisher Scientific). Fifteen micrograms of protein samples were separated using 10 or $12 \%$ SDS-polyacrylamide gel electrophoresis and transferred to nitrocellulose membranes (Hybond ${ }^{\mathrm{TM}} \mathrm{ECL}^{\mathrm{TM}}$; Amersham, Piscataway, NJ, USA). For the blocking step, we incubated the membranes with $5 \%$ non-fat dry milk in 0.05 or $0.1 \%$ Tween-20 TBST, as recommended by each antibody's manufacturer, for $1 \mathrm{~h}$ at room temperature. After washing, the proteins were probed with specific primary antibodies overnight at $4^{\circ} \mathrm{C}$. On the following day, the membranes were incubated with horseradish peroxidase (HRP)-conjugated secondary antibodies (Santa Cruz Biotechnology, Santa Cruz, CA, USA) for $1 \mathrm{~h}$ at room temperature. Details for the antibodies used in this study are provided in Table SII. Proteins were detected by chemiluminescence (ECL, Amersham ${ }^{\mathrm{TM}}$, or Immobilon; Millipore, Billerica, MA, USA) with the LAS-4000 mini machine (GE Healthcare, Freiburg, Germany). The bands of the targeted proteins from the obtained images were quantified with ImageJ software (20) and were normalized to the quantified signal intensity of $\beta$-actin.

Reporter assay. DNA fragments carrying p53-responsive elements, as predicted by the JASPAR database, were amplified by PCR and cloned into the pGL4.24 [luc2P/minP] plasmid (Promega) (primes are presented in Table SI). The known p53 binding site in the promoter region of CDKN1A was used as positive control for human binding site constructs: GAACATGTCCCAACATGTTG (18). For point mutations, the 6th, 13th and 16th nucleotides of the binding site were changed to ' $\mathrm{T}$ ' using site-directed mutagenesis. The H1299 cells were co-transfected with the pGL4.24 control vector or pGL4.24 containing the target p53 binding site, accompanied by the empty vector pcDNA3.1, wild-type p53, or mutant p53 (p53R175H for human p53 and p53R172H for mouse p53) expression vector. All samples were co-transfected with pGL4.74 to normalise the transfection efficiency. Luciferase activities were detected at $48 \mathrm{~h}$ following transfection using the Dual-Glo Luciferase Assay System (Promega) according to the manufacturer's instructions.

Colony formation assay. The full-length INKA2 cDNA with stop codon was cloned into the PCAGGS vector containing an HA-tag (pCAGGSnHC) (primers are presented in Table SI). Cells were seeded (densities of 10,000 cells/well and 5,000 cells/well for HBC4 and U2OS cells, respectively) and grown in 6-well culture plates. On the following day, the PCAGGS/INKA2 or the PCAGGSnHc mock plasmid was transfected into the cells. The U2OS and HBC4 cells were cultured in the presence of 1.0 or $0.4 \mathrm{mg} / \mathrm{ml} \mathrm{Geneticin}{ }^{\circledR}$ (Wako Pure Chemical Industries, Ltd., Osaka, Japan), respectively, for 1 to 2 weeks. Colonies were washed with PBS, fixed with methanol at room temperature for $2 \mathrm{~h}$, and were counted with ImageJ software (20) following overnight staining at room temperature with crystal violet (Sigma-Aldrich). The two-tailed Student's t-test was used to calculate the P-values for the differences between the mock and INKA2-expressing replicates $(n=3)$. 
Immunoprecipitation and deletions in overexpression constructs. The full-length encoding INKA2 and PAK4 cDNAs were cloned into PCAGGS vectors containing a multiple cloning site and HA-tag (pCAGGSnHC) or FLAG-tag (pCAGGSn3FC) (primers are presented in Table SI). Plasmids were transfected into $293 \mathrm{~T}$ cells to induce the overexpression of the target genes. Whole-cell lysates were collected at $48 \mathrm{~h}$ following transfection with a cell lysis buffer consisting of 20 mM Tris (pH 7.5), 150 mM NaCl, 1 mM EDTA, 1 mM EGTA, $1 \%$ Triton X-100, $1 \mathrm{mM}$ PMSF and $0.1 \%$ Protease Inhibitor Cocktail Set III (Calbiochem). Samples were sonicated 3 times for 5 sec each using a Bioruptor UCD-200 (Cosmo Bio). A total of $45 \mu \mathrm{l}$ of the supernatant in each sample was aliquoted as the input sample. Sonicated cell lysates were precleared by incubation with Protein G-Sepharose 4B (Invitrogen/Thermo Fisher Scientific) and normal mouse IgG (1 $\mu \mathrm{g} / \mathrm{sample}$, sc-2027; Santa Cruz Biotechnology) for $1 \mathrm{~h}$ at $4^{\circ} \mathrm{C}$. Precleared cell lysates were immunoprecipitated with mouse monoclonal anti-HA antibody-conjugated agarose beads or mouse monoclonal anti-FLAG antibody-conjugated agarose beads ( $25 \mu \mathrm{g} / \mathrm{sample}$, cat. nos. A2095 and A2220; Sigma-Aldrich). The obtained samples were washed 4 times with $1 \mathrm{ml}$ of ice-cold cell lysis buffer (without PMSF and Protease Inhibitor) and then boiled for 2 min following the addition of Laemmli Sample Buffer (Bio-Rad Laboratories, Hercules, CA, USA). For deletions, the RNRQPLVLGDN (150-160) residues of the INKA2 iBox domain and the catalytic domain (326-591) of PAK4 were deleted by site-directed mutagenesis.

Mass spectrometry. The pCAGGS mock plasmid or pCAGGS/INKA2-HA plasmid were transfected into the 293T cells on the 2 nd day after plating in a $10-\mathrm{cm}$ dish. Whole-cell lysates were collected and immunoprecipitated with an antibody against HA-tag (Table SII). The resulting lysates were subjected to mass spectrometry analysis as previously described (21). Briefly, the samples were reduced in $10 \mathrm{mM}$ tris(2-carboxyethyl)phosphine with $50 \mathrm{mM}$ ammonium bicarbonate (both from Sigma-Aldrich) for $30 \mathrm{~min}$ at $37^{\circ} \mathrm{C}$ and alkylated in $50 \mathrm{mM}$ iodoacetamide (Sigma-Aldrich) with $50 \mathrm{mM}$ ammonium bicarbonate for $45 \mathrm{~min}$ in the dark at $25^{\circ} \mathrm{C}$. Trypsin/Lys-C (Promega) solution was added followed by incubation at $37^{\circ} \mathrm{C}$ for $12 \mathrm{~h}$. The resulting peptides were extracted from the gel fragments and analysed with an Orbitrap Fusion Lumos mass spectrometer (Thermo Fisher Scientific) combined with the UltiMate 3000 RSLC nano-flow HPLC system (Thermo Fisher Scientific) in HCD MS/MS mode. The MS/MS spectra were searched against the Homo sapiens protein sequence database in SwissProt using the Mascot or Sequest search engine in the Proteome Discoverer 2.2 software (Thermo Fisher Scientific), in which peptide identification filters were set at 'false discovery rate $<1 \%$ ' and 'Mascot expectation value $<0.05$ or Sequest XCorr $>2.0$ '.

ATP assay. Cells stably expressing mock vector or INKA2 were cultured in medium with $1 \mu \mathrm{g} / \mathrm{ml}$ of Dox for at least $48 \mathrm{~h}$ before seeding. Cells were seeded on 24-well plates and were cultured for 4 days. Cell viability was evaluated by Cell Titer-Glo Luminescent Cell Viability assay (Promega) at the 24-, 48-, 72- and 96-h time-points according to the manufacturer's instructions. Briefly, tge culture medium was removed and cells were incubated with a mix of $100 \mu \mathrm{l}$ of Cell Titer-Glo reagent and $100 \mu \mathrm{l}$ of culture medium for $10 \mathrm{~min}$. The luminescence of the cell lysates was measured using the ARVO X3 plate reader (Perkin-Elmer, Waltham, MA, USA).

The Cancer Genome Atlas (TCGA) analysis. Wholetranscriptome sequencing data, transcriptome profiling microarray data, and p53 mutation status were obtained from TCGA database using cBioPortal $(22,23)$. We downloaded and analysed datasets for 20 cancer cohorts: Bladder urothelial carcinoma (BLCA), breast invasive carcinoma (BRCA), cervical and endocervical cancers (CESC), cholangiocarcinoma (CHOL), colorectal adenocarcinoma (COAD/READ), glioma (GBM/LGG), head and neck squamous cell carcinoma (HNSC), pan-kidney cohort (KIPAN), acute myeloid leukaemia(LAML), liver hepatocellular carcinoma (LIHC), lung adenocarcinoma (LUAD), lung squamous cell carcinoma (LUSC), ovarian serous cystadenocarcinoma (OV), pancreatic adenocarcinoma (PAAD), pheochromocytoma and paraganglioma (PCPG), prostate adenocarcinoma (PRAD), skin cutaneous melanoma (SKCM), stomach adenocarcinoma (STAD), thyroid carcinoma (THCA) and uterine corpus endometrial carcinoma (UCEC). The two-tailed Student's t-test was used to calculate the P-values for differences between the compared groups. The number of samples is presented in Table SIV. We excluded the cancer type when the number of samples was not relevant. Data regarding the DNA methylation status of the INKA2 promoter region were downloaded from the MethHC database (24).

\section{Results}

Screening for p53 downstream targets. In this study, we applied known DNA double-strand break induction, such as $\mathrm{X}$-ray irradiations and ADR, to activate p53 expression and the transcription of its downstream targets. We first screened the RNA sequencing (RNA-seq) data obtained from 4 groups of mice, p53 wild-type mice (W), p53 knockout mice (K), treated with (WX and KX) or without 10 Gy of whole-body $\mathrm{X}$-ray irradiation. For each mouse, the total RNA extracted from 24 tissues was subjected to RNA-seq analysis $(11,12)$. Among 23,813 genes, we first excluded transcripts with an extremely low expression in all organs (FPKM <1). Subsequently, we compared the median expression of the WX group with the maximum median expression among the rest (K, KX or $\mathrm{W})$. Transcripts displaying a significantly upregulated expression in the WX group by at least 3 -fold in 10 or more organs were selected (Table SV). In total, 22 genes fulfilled our criteria, including 13 genes that were previously reported as p53 downstream targets: Mgmt (9), LIF, interleukin 6 family cytokine (Lif) (25), sestrin 2 (Sesn2) (26), D630023F18Rik (27), BCL2 binding component 3 (Bbc3) (28), cyclin G1 (Ccngl) (29), zinc finger protein 365 (Zfp365) (30), 1700007K13Rik (31), pleckstrin homology like domain family A member 3 (Phlda3) (32), proline and serine rich coiled-coil 1 (Psrcl) (33), cyclin dependent kinase inhibitor 1A (Cdknla) (18), growth differentiation factor 15 (Gdf15) (34) and ectodysplasin A2 receptor (Eda2r) (35). Notably, well-known p53 downstream targets, such as Cdknla and Eda2r, exhibited the highest number of organs satisfying the screening criteria. The rest 
Table I. List of the genes obtained from the screening in mouse transcriptome data.

\begin{tabular}{|c|c|c|}
\hline Gene name & $\begin{array}{l}\text { Number of mouse organs satisfying } \\
\text { screening criteria }^{a}\end{array}$ & $\begin{array}{c}\text { Reported as p53 } \\
\text { downstream target }\end{array}$ \\
\hline Plcd4 & 10 & Unreported, candidate \\
\hline Mgmt & 10 & Reported \\
\hline 4632434I11Rik & 11 & Unreported, candidate \\
\hline $\operatorname{Ces} 2 e$ & 11 & Unreported, no human homolog \\
\hline Lif & 11 & Reported \\
\hline $\operatorname{Sesn} 2$ & 11 & Reported \\
\hline$C d 80$ & 12 & Unreported, candidate \\
\hline Inka2/Fam $212 b$ & 12 & Unreported, candidate \\
\hline A930001C03Rik & 12 & Unreported, non-coding RNA, no human homolog \\
\hline D630023F18Rik & 13 & Reported \\
\hline$B b c 3$ & 13 & Reported \\
\hline 9030617003Rik & 13 & Unreported, candidate \\
\hline Celf5 & 13 & Unreported, candidate \\
\hline Ccngl & 14 & Reported \\
\hline Zfp365 & 14 & Reported \\
\hline 1700007K13Rik & 14 & Reported \\
\hline Phlda3 & 15 & Reported \\
\hline Psrcl & 15 & Reported \\
\hline Gm16197 & 16 & Unreported, non-coding RNA \\
\hline Cdknla & 17 & Reported \\
\hline Gdf15 & 22 & Reported \\
\hline$E d a 2 r$ & 23 & Reported \\
\hline
\end{tabular}

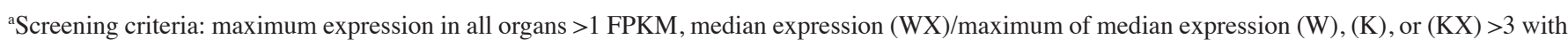
significance $(\mathrm{P}<0.05)$ in not less than 10 organs. FPKM, fragment per kilobase million; $\mathrm{W}, p 53^{+/+} ; \mathrm{WX}$, irradiated $p 53^{+/+} ; \mathrm{K}, p 53^{-/-} ; \mathrm{KX}$, irradiated $p 5^{3-/}$.

of the resulting genes consisted of 2 non-coding RNAs, one gene without any corresponding human homolog, and 6 genes remaining as candidates: Fam212b (Inka2), 4632434I11Rik (Ddias), Celf5, $9030617003 R i k, C d 80$ and Plcd4 (Table I).

We then examined the expression of the remaining 6 candidate genes in human cells using cDNA microarray performed in two different cell lines $(12,13)$. The induction of gene expression was induced by ADR instead of irradiation for experimental convenience. The $p 53$ wild-type $\left(p 53^{+/+}\right)$or knockout $\left(p 53^{-/}\right)$HCT116 colorectal carcinoma and MCF10A breast epithelial cells were treated with ADR for $2 \mathrm{~h}$. Total RNA was extracted at 4 time-points following treatment, namely at $0,12,24$ and $48 \mathrm{~h}$, and subjected to a cDNA microarray analysis. We considered the $p 53^{-/}$group and untreated samples $(0 \mathrm{~h})$ as a cluster. The maximum expression in the cluster was compared to the median expression of the $p 53^{+/+}$ ADR-treated group ( $p 53^{+/+}$ADR 12, 24 and 48 h). We selected genes displaying a significant upregulation in expression of at least 1.5 -fold in the $p 53^{+/+}$ADR induction group for further investigation (Fig. 1A and B). Notably, INKA2 was the only gene which exhibited an induction in expression by ADR treatment in the $p 53^{+/+}$cells. The expression of this gene was significantly increased by 1.61 - and 2.19-fold in the HCT116 and MCF10A cells, respectively (Fig. S2A).

We obtained INKA2, also known as FAM212B, as the only gene satisfying all criteria in the screen. In the mouse transcriptome data, Inka2 exhibited an increase expression in the WX group that was significantly induced $>3$-fold in 12 of 24 organs (Fig. 1C). Its expression was upregulated over 5-fold in the colon, liver, mammary gland and calvaria (skull), over 10-fold in the bone marrow, ovary and spleen, and over 20-fold in the kidney (Fig. S2B). The induction was insignificant or significant, but $<3$-fold in the other mouse tissues (Fig. S2B and C).

INKA2 expression is induced in a p53-dependent manner. We further investigated the association between INKA2 and p53 expression using human cancer cell lines. Although INKA2 has 2 mRNA isoforms, the second isoform exhibited insufficient expression levels for analysis (Fig. S3). Therefore, we focused our study on isoform 1 of INKA2, the major transcript. Its expression was found with the highest induction in HBC4 human breast cancer cells and U2OS osteosarcoma cells; thus, we conducted further experiments using these two cell lines. The mRNA levels of INKA2 in both cell lines were evaluated by RT-qPCR. A significant increase in the mRNA levels of the INKA2 was observed in the cells treated with ADR. However, the expression was suppressed when $p 53$ expression was silenced using siRNA (Fig. 2A). A siRNA against enhanced green fluorescent protein (EGFP) was used as the negative control. We then we performed a western blot analysis of U2OS cell lysates cultured under the 

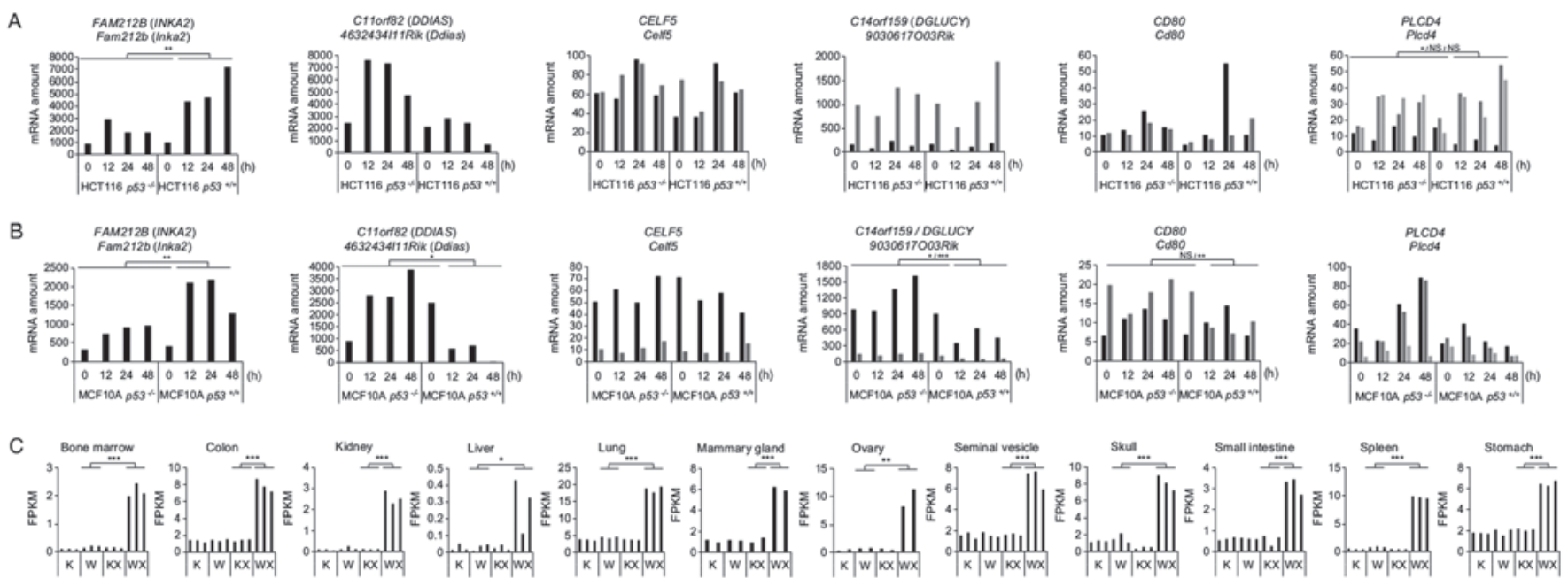

Figure 1. Expression levels of candidate genes in mouse and human transcriptome data. (A and B) Expression levels of the 6 candidate gene mRNAs in human wild-type $p 53\left(p 53^{+/+}\right)$or knockout $\left(p 53^{-/-}\right)$(A) HCT116 colorectal carcinoma cells and (B) non-tumourigenic breast epithelial cells MCF10A harvested at 0,12 , 24 or $48 \mathrm{~h}$ following treatment with ADR. Cells were treated with 2 and $0.5 \mu \mathrm{g} / \mathrm{ml}$ of ADR for $2 \mathrm{~h}$ for the HCT116 and MCF10A cells, respectively. Different isoforms are represented by bars of different shades of grey and black. P-values were calculated between $p 53^{+/+}$cells $12,24,48 \mathrm{~h}$ and the group comprising $p 53^{-/}$cells $0,12,24,48 \mathrm{~h}$ and $p 53^{+/+}$cells $0 \mathrm{~h}$ using one-way ANOVA ; ${ }^{\circ} \mathrm{P}<0.05,{ }^{* * *} \mathrm{P}<0.01$ and ${ }^{* * * *} \mathrm{P}<0.001$; NS, not statistically significant. (C) Levels of the Inka 2 mRNA in the mouse tissues satisfying the screening criteria. RNA-seq was performed on tissues from untreated p53 wild-type (W) or knockout (K) mice, or on those dissected $24 \mathrm{~h}$ following irradiation with $10 \mathrm{~Gy}$ of X-rays (WX and KX). The expression levels are represented in fragments per kilobase million (FPKM). P-values were calculated between the WX group and the group with a maximum median expression among the W, K and KX groups by one-way ANOVA with Dunnett's post hoc test; ${ }^{*} \mathrm{P}<0.05,{ }^{* *} \mathrm{P}<0.01$ and ${ }^{* * *} \mathrm{P}<0.001$. ADR, adriamycin; Inka2, inka box actin regulator 2.

same experimental conditions (Fig. 2B). The amount of p53 protein increased in the cells treated with ADR and decreased in the cells transfected with p53 siRNA. We used CDKN1A as the positive control. INKA2 and CDKN1A exhibited similar expression patterns. Thus, these results suggest that the mRNA and protein expression of INKA2 is regulated via a p53-dependent mechanism.

We designed 2 siRNAs targeting INKA2 to evaluate the quality of the antibody against INKA2. The results of RT-qPCR confirmed the silencing of the mRNAs by the siRNAs (Fig. 2C). The results of western blot analysis also revealed the loss of the band corresponding to INKA2 in the cells transfected with the siRNAs, indicating the specificity of the antibody (Fig. 2C). Finally, we performed immunocytochemistry to validate the induction of INKA2 expression by p53 and the repression of INKA2 by the siRNAs (Fig. 2D).

In addition to the intracellular expression, we analysed the INKA2 mRNA expression levels in tumour tissues from all cancer types of the TCGA database presenting adequate data and sample size. We observed significantly a higher INKA2 expression in $p 53$ wild-type samples compared with $p 53$ mutant samples in 4 cohorts: BLCA, COAD/READ, KIPAN and PRAD (Fig. 2E). Consequently, INKA2 showed a p53-dependent expression pattern at both the cellular and tissue levels, indicating that the expression of this gene is regulated by 553 .

INKA2 is a direct p53 downstream target. We inspected data obtained from chromatin immunoprecipitation coupled with deep sequencing (ChIP-seq) targeting the $\mathrm{p} 53$ protein to examine whether p53 directly regulates INKA2 expression. In human samples, the ChIP-seq results from the ReMap 2018 database (15) revealed p53 accumulation at 3 regions of the INKA2 gene: 15 and $7.5 \mathrm{~kb}$ upstream of the first exon of isoform 1 and throughout the first exon of isoform 1 (Fig. S4A). Further investigations using the JASPAR database (17) identified a putative p53 binding site located approximately 600 bases downstream of the first exon of isoform 1 (Fig. 3A and B). The binding site is adjacent to the INKA2 promoter (Fig. S4A) and overlaps with the third ChIP-seq peak region (Table SVI). Moreover, the ENCODE histone marks data (36) integrated in the UCSC Genome Browser (37) revealed an enrichment of $\mathrm{H} 3 \mathrm{~K} 4 \mathrm{me} 1$ and $\mathrm{H} 3 \mathrm{~K} 4 \mathrm{me} 3$ histone methylation and H3K27Ac histone acetylation marks in the same region, implicating chromatin remodelling and transcriptional regulation at the putative p53-responsive site (Fig. S4A).

Likewise, we identified a p53-responsive element in the mouse Inka2 sequence using ChIP-seq data of mouse embryonic fibroblasts (MEFs) treated with $0.2 \mu \mathrm{g} / \mathrm{ml}$ of ADR for $12 \mathrm{~h}$, obtained from the ChIPBase database (16) (Fig. S4B). We then employed the JASPAR database to predict p53-responsive elements in the ChIP-seq results. Similar to the human one, the putative p53 binding site was located approximately 600 bases downstream of the first exon of isoform 1 (Fig. 3A and B). The sequence is adjacent to the Inka 2 promoter (Fig. S4B) and overlaps with the ChIP-seq peak (Table SVII). The putative p53 binding sites predicted by the JASPAR database comprised 2 repeated palindromic nine-base half-sites. A similarity of $94.4 \%$ was observed between the sequences of the 2 species, only differing from the 9th nucleotide where a ' $\mathrm{T}$ ' in the human sequence was replaced with a ' $\mathrm{C}$ ' in the mouse sequence (Fig. 3B). In addition to the JASPAR p53 motif, the putative binding site sequence largely resembles to a high prediction accuracy consensus p53 binding motif (18) (Fig. S1). The absolute scores calculated from the position weight matrix of the JASPAR database were 9.21 and 10.85 for human and mouse, respectively (Fig. 3B). Known p53 downstream targets have been reported to disfavour spacer between the 

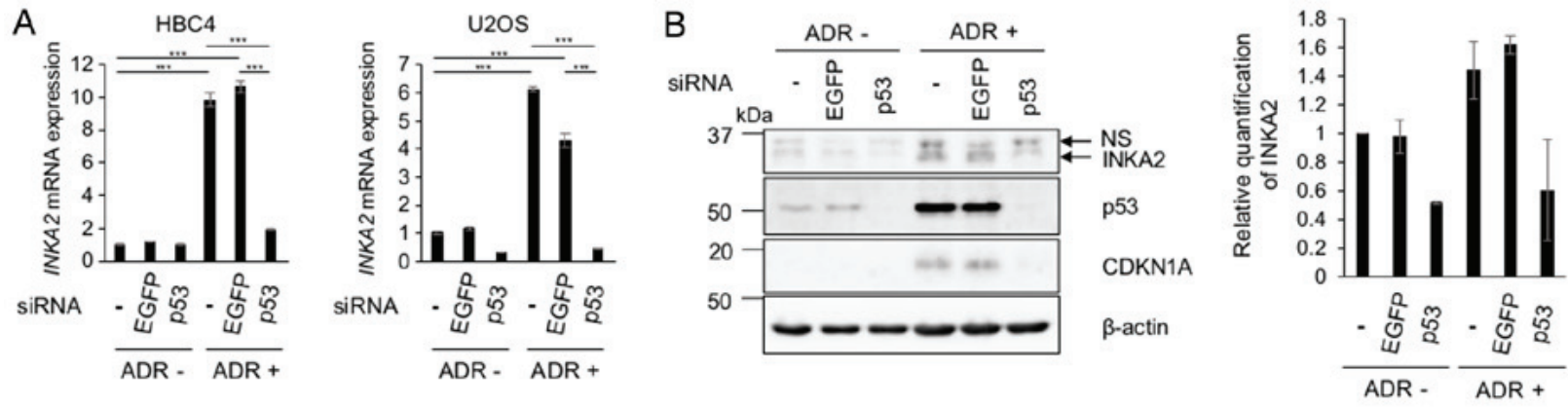

C
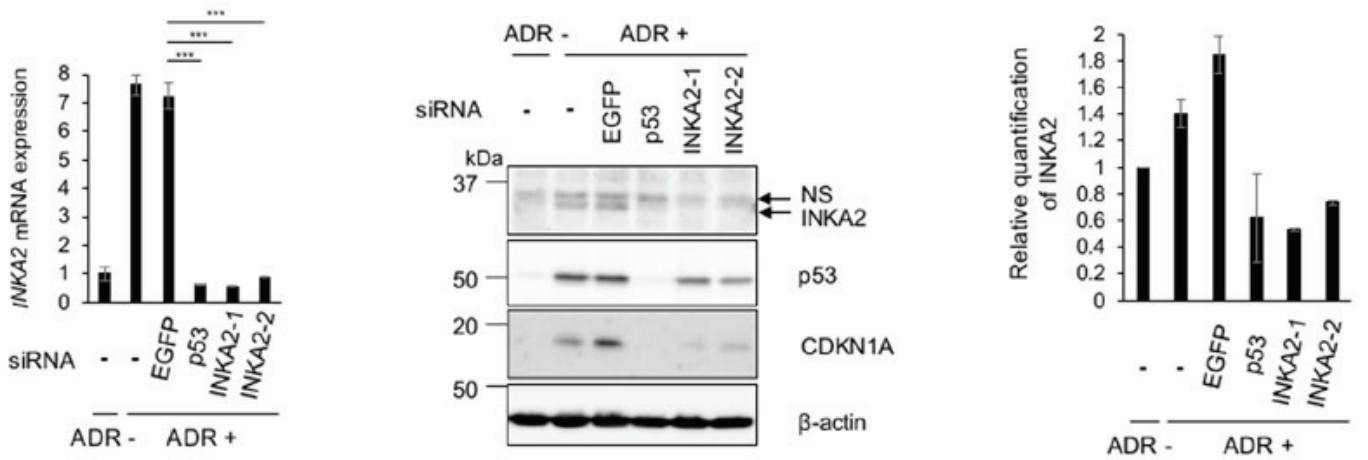

D

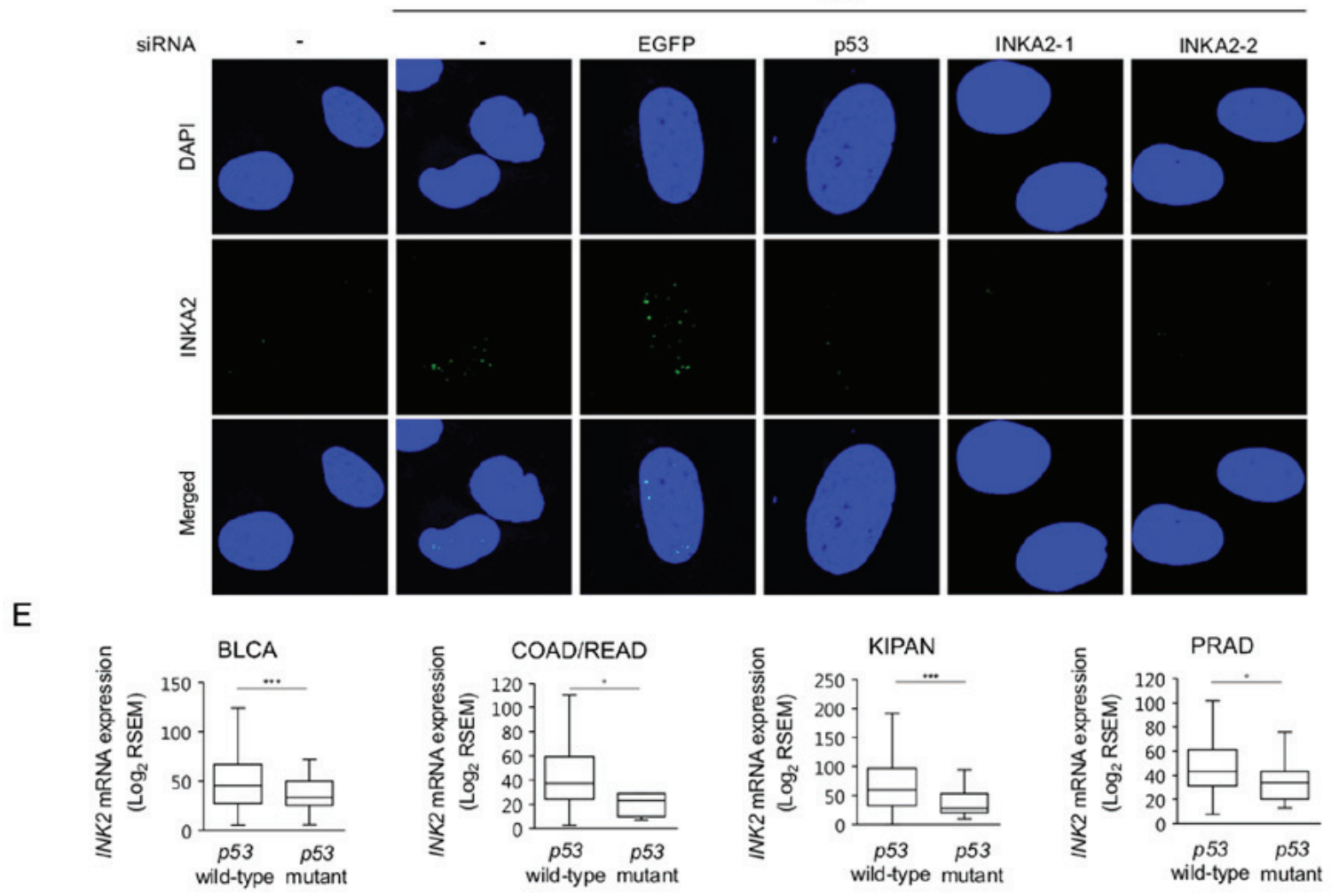

Figure 2. INKA2 is a p53 downstream target. (A) Relative mRNA expression of INKA2 normalised to GAPDH mRNA in HBC4 and U2OS cells transfected with or without an siRNA targeting either EGFP or p53 and treated with or without ADR. The expression of the untreated sample (siRNA-, ADR-) is considered 1. Cells were treated with $2 \mu \mathrm{g} / \mathrm{ml}$ of ADR for $2 \mathrm{~h}$. Data were analysed using one-way ANOVA with Tukey's HSD post hoc test; ${ }^{* * *} \mathrm{P}<0.001$. Error bars are the means $\pm \mathrm{SD}, \mathrm{n}=2$. (B) Western blot analysis of levels of the INKA2, p53 and CDKN1A proteins in U2OS cells transfected with or without the siRNAs and treated with or without ADR. $\beta$-actin is shown as a loading control. Cells were treated with $2 \mu \mathrm{g} / \mathrm{ml}$ of ADR for $2 \mathrm{~h}$. The bands detected by anti-INKA2 antibody were quantified and normalised to $\beta$-actin. The untreated sample (siRNA-, ADR-) is considered 1 . Error bars are the means \pm SD, $\mathrm{n}=3$. NS, non-specific. (C) RT-qPCR and western blot analyses of INKA2 levels in U2OS cell lines transfected with 2 siRNAs against INKA2. GAPDH was used for the normalization of mRNA expression. The expression of the untreated sample (siRNA-, ADR-) is considered 1. P-values were calculated by comparing si-EGFP ADR+ to si-p53 ADR+ and si-INKA2 ADR+ using one-way ANOVA with Tukey's HSD post hoc test; ${ }^{* * *} \mathrm{P}<0.001$. The bands detected by anti-INKA2 antibody were quantified and normalised to $\beta$-actin. The untreated sample (siRNA-, ADR-) is considered 1. NS, non-specific. Error bars are the means \pm SD, $\mathrm{n}=2$. (D) Immunocytochemical staining of U2OS cells transfected with the siRNAs and treated with ADR. Cells were stained with DAPI (blue) and an antibody against INKA2 (green). Cells were treated with $2 \mu \mathrm{g} / \mathrm{ml}$ of ADR for $2 \mathrm{~h}$. (E) Comparison of the levels of INKA2 mRNA in Log 2 RSEM between TCGA $p 53$ wild-type and $p 53$ mutant for BLCA, COAD/READ, KIPAN and PRAD tumour tissues. Data were analysed using a two-tailed Student's t-test; ${ }^{*} \mathrm{P}<0.05$ and ${ }^{* * *} \mathrm{P}<0.001$. INKA2, inka box actin regulator 2; ADR, adriamycin; BLCA, bladder urothelial carcinoma; COAD/READ, colorectal adenocarcinoma; KIPAN, pan-kidney cohort; PRAD, pancreatic adenocarcinoma. 

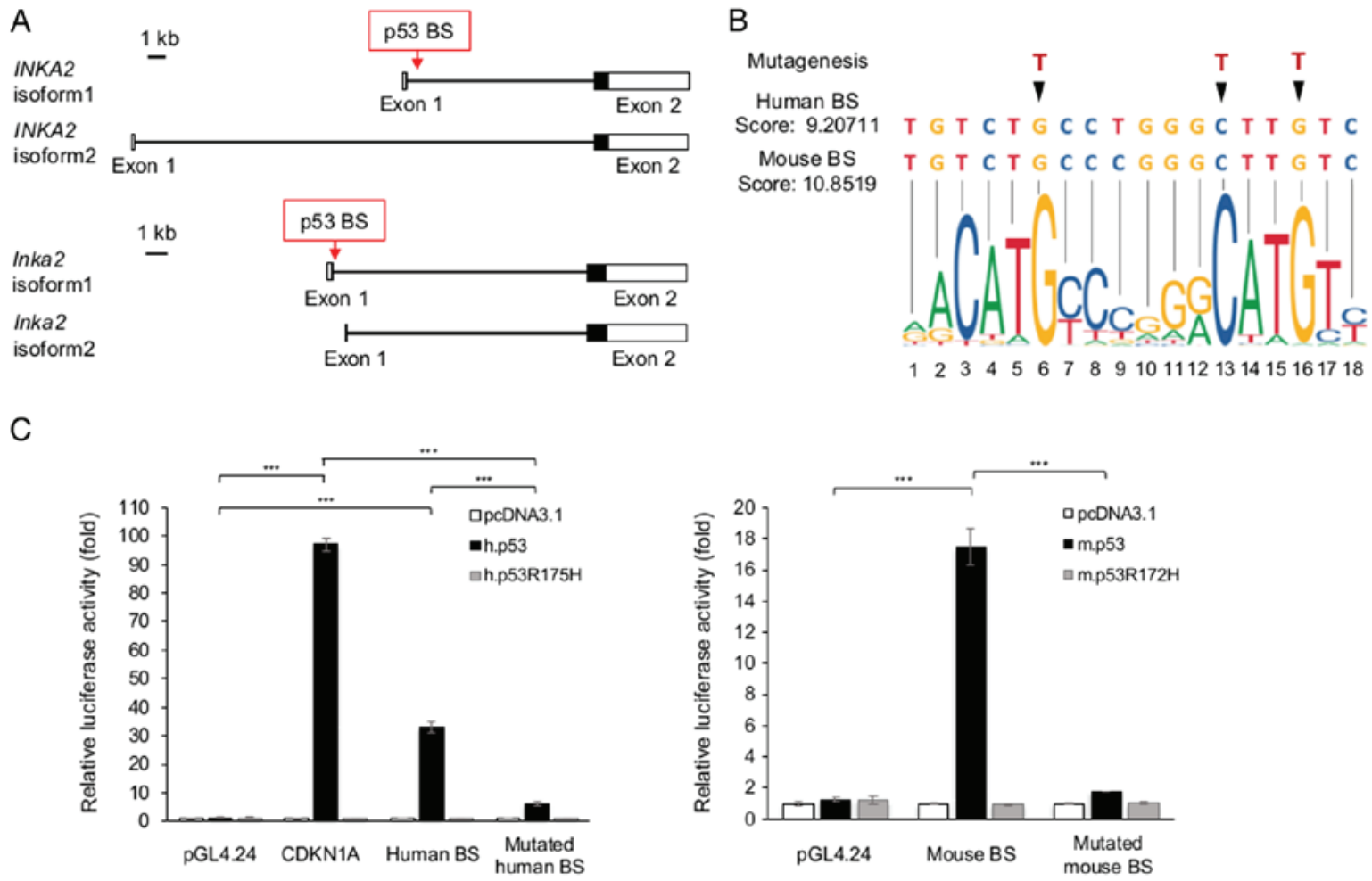

Figure 3. INKA2 is a direct target of p53. (A) Genomic structure of the human INKA2 gene (top panel) and mouse Inka2 gene (bottom panel). Filled box, coding region; unfilled box, non-coding region; horizontal line, intron; p53 BS, p53 binding site. (B) The p53 binding sites (BS) identified in human and mouse INKA2/Inka2 were aligned with the JASPAR model. Nucleotides that were modified by mutagenesis are indicated by arrows. (C) Luciferase assay of H1299 cells expressing the empty vector pGL4.24, BS construct, or mutated BS constructs of the human (left panel) and mouse (right panel) genes, performed as described in (B). The control vector pcDNA3.1, human or mouse wild-type p53 or mutant p53 were co-transfected simultaneously. Luciferase activity is indicated relative to the activity of the control vectors pcDNA3.1 and pGL4.24. The p53 binding site sequence in the promoter region of $C D K N 1 A$ was used as a positive control. h.p53, human p53; h.p53R175H, mutant human p53 R175H; m.p53, mouse p53; m.p53R172H, mutant mouse p53 R172H. Error bars are the means $\pm \mathrm{SD}, \mathrm{n}=3$. Data were analysed using one-way ANOVA with Tukey's HSD post hoc $\mathrm{t}$-test; ${ }^{* * *} \mathrm{P}<0.001$. INKA2, inka box actin regulator 2 .

2 half-sites of the binding site (18). The putative binding sites were consecutive half-sites and this confirmed a prediction specificity. Further inspection of the binding site sequences indicated a high level of conservation across species (Fig. S5), revealing its importance.

We then performed luciferase reporter assays in the H1299 cells expressing wild-type human p53 or the p53R175H mutant, or wild-type mouse p53 or the p53R172H mutant (Fig. 3C). The reported p53 binding site in CDKN1A was used as a positive control (18). The p53 protein interacted with the predicted binding site when both p53 and the binding site sequences were wild-type. Luciferase activity decreased when point mutations, as shown in Fig. 3B, were introduced into the responsive element sequences. Similarly, luciferase activity decreased in the presence of mutant $\mathrm{p} 53$. Thus, INKA2 is directly regulated by $\mathrm{p} 53$.

INKA2 functions as a cancer cell growth inhibitor. As regards the association between INKA2 and tumours, we investigated its role in cancer cell growth by performing colony formation assays using the HBC4 and U2OS cells (Fig. 4A). A total of 20 to $40 \%$ fewer colonies were formed by cells overexpressing INKA2 compared with the mock vector. Subsequently, it was concluded that INKA2 reduces cancer cell proliferation to a certain extent.

We further analysed INKA2 expression data from the TCGA database. Among all available cancer datasets,
INKA2 was expressed at lower levels in the tumour samples than in the control samples in multiple cancer types: BRCA, COAD, KIRC + KIRP, LUAD, LUSC, PRAD and THCA (Fig. 4B). Additionally, the promoters of the human and mouse INKA2 genes contained CpG islands (Fig. S4). A higher DNA methylation was observed in the human INKA2 promoter region in the tumour samples than in the control samples (Fig. 4C), explaining the down-regulation of INKA2 expression in tumour samples. These results indicate that DNA methylation and p53 mutations synergistically suppresses INKA2 expression in cancer tissues. Furthermore, the p53 mutation status is associated with INKA2 expression, but not with DNA methylation. Taken together with the reduction of cancer cell growth, it is thus suggested that INKA2 may function as a cancer cell growth inhibitor.

INKA2 interacts with p21 (RACl) activated kinase 4. Using an antibody against HA-tag, we performed immunoprecipitation using whole-cell lysates obtained from 293T cells overexpressing HA-tagged INKA2 to determine its function in human cells. The samples were then subjected to mass spectrometric analysis (Table II). The results revealed a high binding capacity of INKA2 to PAK4, a serine/threonine-protein kinase. In fact, INKA1, a member of the same INKA protein family, has been reported as an inhibitor of PAK4 kinase (38). Both INKA1 and INKA2 contain an iBox domain of 38 amino acids (Fig. 5A). On the other hand, PAK4 contains 
A

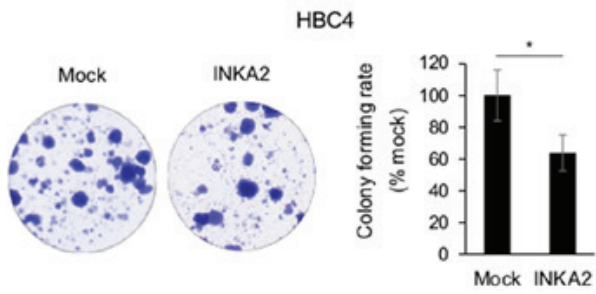

U2OS
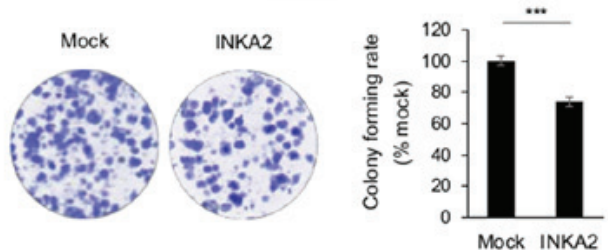
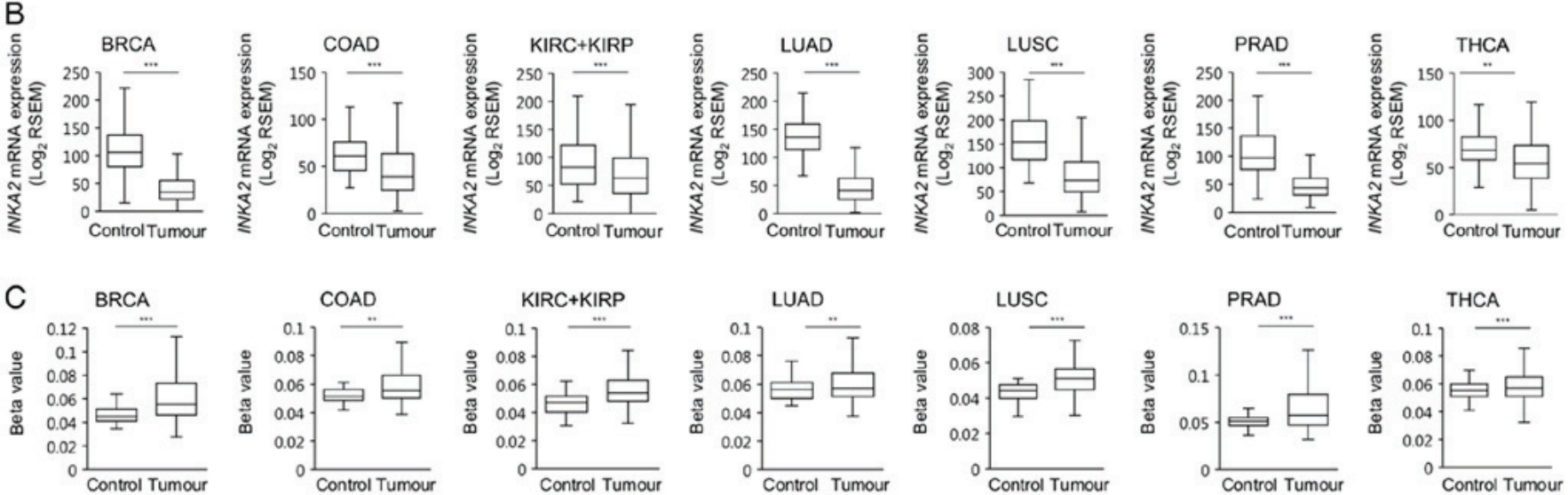

Figure 4. INKA2 functions as a cancer cell growth inhibitor. (A) Results of the colony formation assay performed with HBC4 (left panel) and U2OS (right panel) cells overexpressing the mock vector or INKA2. The number of colonies in the mock-transfected cells is considered $100 \%$. Error bars are the means $\pm \mathrm{SD}, \mathrm{n}=3$. (B and C) Differential expression of the (B) INKA2 mRNA in $\log _{2}$ RSEM and (C) DNA methylation level at the INKA2 promoter region in TCGA control and tumour samples. Data were analysed with a two-tailed Student's t-test; ${ }^{*} \mathrm{P}<0.05,{ }^{* *} \mathrm{P}<0.01$ and ${ }^{* * * *} \mathrm{P}<0.001$. INKA2, inka box actin regulator 2 . BRCA, breast invasive carcinoma; COAD, colon adenocarcinoma; KIRC+KIRP, kidney renal clear cell and papillary cell carcinoma; LUAD, lung adenocarcinoma; LUSC, lung squamous cell carcinoma; PRAD, prostate adenocarcinoma; THCA, thyroid carcinoma.

an auto-inhibitory domain (AID) that interacts with the substrate-docking site situated in the catalytic domain via the RPK peptide: $\mathrm{R}^{49}$ PKPLVDP $(39,40)$ (Fig. 5A and B). The iBox domain also includes a tripeptide PLV that is shared by the RPK sequence in PAK4-AID (Fig. 5A). Thus, the iBox peptide is likely able to bind to the substrate-docking site of PAK4 in the same manner as PAK4-AID. Compared with INKA1, INKA2 maintains the iBox domain (137-174) with a high degree of sequence identity, where the essential PAK4-inhibitory motif is NRQPLVLG instead of SRQPLVLG (Fig. 5A). Moreover, the iBox domain is highly conserved across species (Fig. 5C), indicating the importance of the sequence in the cell.

We immunoprecipitated INKA2 proteins ectopically expressed in $293 \mathrm{~T}$ cells with an anti-HA antibody to confirm the interaction between INKA2 and PAK4 (Fig. 6A). Subsequent western blot analysis of PAK4 confirmed the binding of INKA2 to PAK4. The same and reciprocal results were obtained from $293 \mathrm{~T}$ cells overexpressing both HA-tagged INKA2 and FLAG-tagged PAK4 proteins (Fig. 6B). We then constructed 2 plasmids overexpressing partially deleted INKA2 and PAK4 proteins. The PAK4-inhibitory motif was deleted in INKA2 $\triangle 150-160$, and part of the C-terminal catalytic domain (326-591) was deleted in PAK4 1-325 (Fig. 5B). These domains have been reported to interact with each other and a deletion will interrupt the bound (38). Following immunoprecipitation, both deletions disrupted the interaction between INKA2 and PAK4, suggesting that the targeted binding motif of iBox was located in the kinase domain of PAK4 (Fig. 6C). Consequently, we hypothesized that INKA2 inhibits the kinase activity of PAK4 in the same manner as INKA1.
INKA2 downregulates $\beta$-catenin expression at the protein level. Among a large number of substrates, PAK4 interacts with $\beta$-catenin and phosphorylates at Ser675 to regulate its nuclear and cytoplasmic transportation (41). Ser675 phosphorylation protects $\beta$-catenin from the destruction complex and thus stabilises the protein in the cytoplasm (41). Thus, we hypothesised that INKA2 binds to the substrate-docking site within the catalytic domain of PAK4 and inhibits the phosphorylation of $\beta$-catenin Ser675. Subsequently, the protein becomes unstable and hence degraded. We generated a HCT116 cell line with a tetracycline-regulated lentiviral vector system stably expressing INKA2 in the presence of Dox to confirm our hypothesis. The HCT116 cells were selected for the low baseline expression of endogenous INKA2. Western blot analyses indicated decreased intracellular $\beta$-catenin levels in cells overexpressing INKA2 (Fig. 6D). Immunocytochemistry produced similar results (Fig. 6E), suggesting that INKA2 potentially inhibits the kinase function of PAK4 in the same manner as INKA1.

We also performed ATP assay using the INKA2-expressing HCT116 cells to evaluate the suppression of cell growth in four days (Fig. 6F). The results revealed an insignificant difference between INKA2-overexpressing cells and other cells. This indicates that INKA2 inhibits cancer cell growth at a longer time-point of approximately 2 weeks, as shown by the colony formation assays.

\section{Discussion}

The inka box actin regulator (INKA) gene family is evolutionarily conserved among vertebrates and comprises 


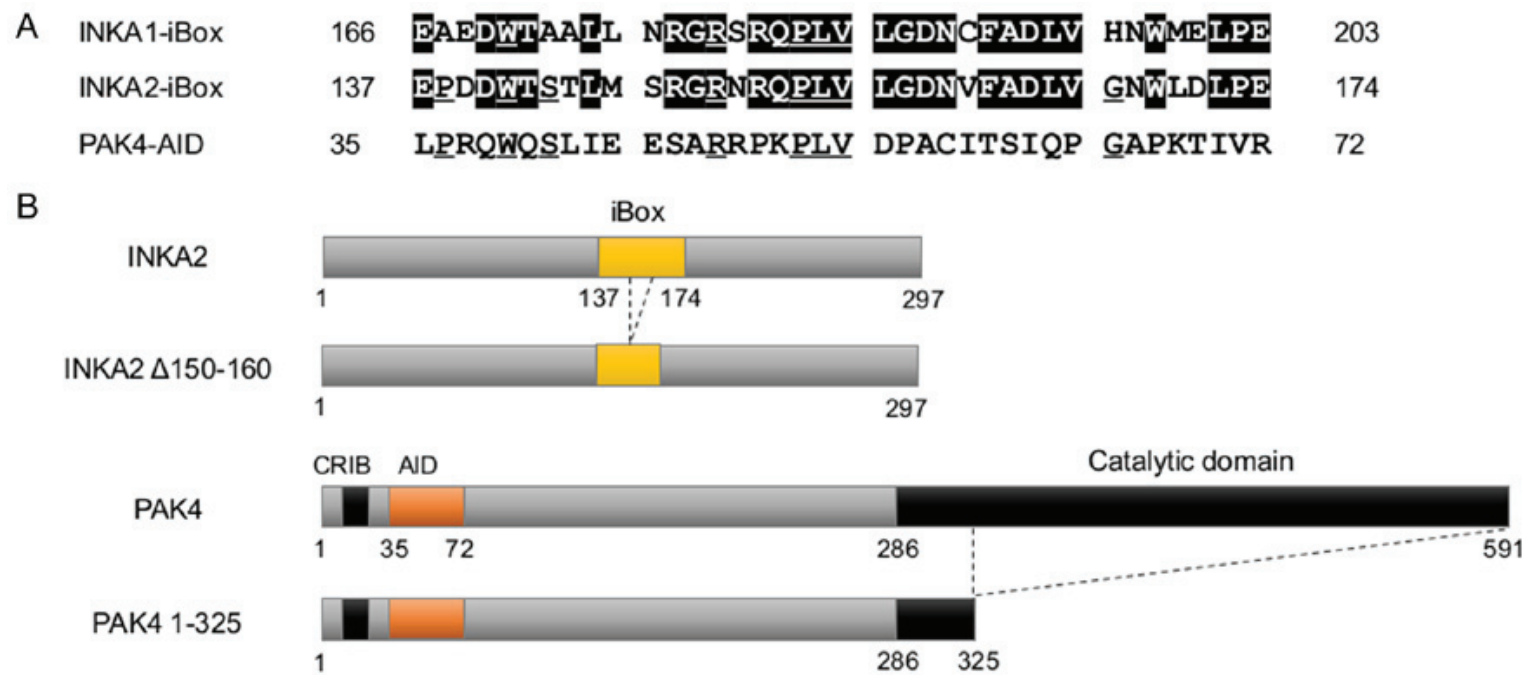

C Homo sapiens (human)
Bos Taurus (cow)
Danio rerio (zebrafish)
Equus caballus (horse)
Felis catus (cat)
Gallus gallus (chicken)
Macaca mulatta (rhesus)
Mus musculus (mouse)
Rattus norvegicus (rat)
Sus scrofa (pig)
Xenopus laevis (frog)
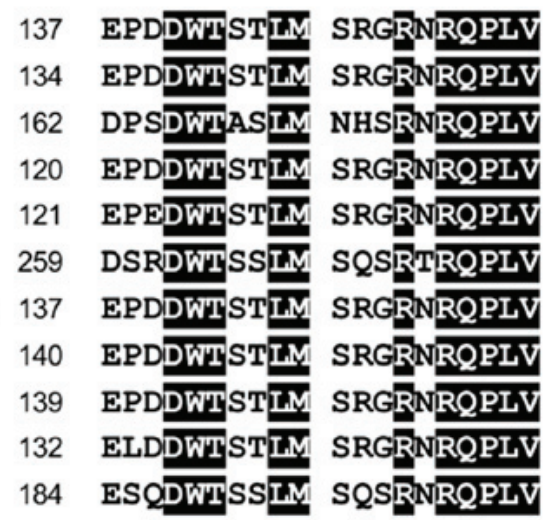

LGDNVFADLV
LGDNVFADLV
LGDNVFADLV
LGDNVFADLV
LGDNVFADLV
LGDNIFADLV
LGDNVFADLV
LGDNVFADLV
LGDNVFADLV
LGDNVFADLV
LGDNVFADLV

\begin{tabular}{ll}
\hline GNWLDLPE & 174 \\
\hline GNWLDLPE & 171 \\
\hline GNWLDLPE & 199 \\
\hline GNWLDLPE & 157 \\
\hline GNWLDLPE & 158 \\
\hline GNWLDLPE & 296 \\
\hline GNWLDLPE & 174 \\
\hline GNWLDLPE & 177 \\
\hline GNWLDLPE & 176 \\
\hline GNWLDLPE & 169 \\
\hline GNWLDLPE & 221
\end{tabular}

Figure 5. INKA2 contains the conserved iBox domain with the PLV tripeptide. (A) Sequence alignments of human INKA1 iBox, INKA2 iBox, and PAK4-AID Residues shaded in black indicate the identity with INKA1 iBox. Underlined residues indicate the identity with PAK4-AID. (B) Structure of INKA2 (top panel), PAK4 (bottom panel), and deletion mutant proteins used for immunoprecipitation. CRIB, Cdc42- and Rac-interactive binding domain; AID, auto-inhibitory domain. (C) Sequence alignments of INKA2 iBox between different species. Identical residues are shaded in black. INKA2, inka box actin regulator 2; PAK4, p21 (RAC1) activated kinase 4.

2 genes in the majority of species: INKAI and INKA2. Both genes share an iBox, or Inka box domain, with an average sequence conservation of $35-40 \%$ across species. The Inkal gene has been studied in mouse, zebrafish and Xenopus embryogenesis and is specifically expressed in neural crest cells (42). In a Xenopus model, cytoskeletal dynamics have been shown to be regulated through the interaction of inkal with p21 (RAC1) activated kinase 5 (42). The knockdown of inkal causes severe defects in both Xenopus and zebrafish embryos, suggesting its essential role in development (42). In a mouse model, the Inkal gene affects neural tube closure, and a deficiency in the protein causes exencephaly (43). By contrast, Inka2 is expressed in the murine nervous system and is involved in mechanisms regulating the actin cytoskeleton and actin-driven processes (44). However, to date, the function of INKA2 has not been investigated either in human cells or in patients with cancer, at least to the best of our knowledge.

Our screening strategy successfully identified a novel p53 downstream target, INKA2/Inka2, in human cells and mouse tissues. The induction of $\mathrm{p} 53$ expression increased the expression of INKA2 at both the mRNA and protein level. The p53 protein regulates INKA 2 by directly interacting with a highly conserved intronic p53 binding motif. Furthermore, INKA2 is expressed at lower levels in several different tumours, and the colony formation assay revealed an association between INKA2 and cancer cell growth. Taken together, this study identified the potential of INKA2 to function as a cancer cell growth inhibitor.

Although the role of INKA2 in cancer remains uncertain, in this study, we identified PAK4 as one of the proteins interacting with INKA2. In this study, INKA2 bound to the kinase domain of PAK4 via iBox, a highly conserved protein domain. Our results provide evidence that INKA2 represses the expression of $\beta$-catenin, a substrate of PAK4, at the protein level. In fact, the activation of $\beta$-catenin and the Wnt/ $\beta$-catenin signalling pathway have been implicated in the carcinogenesis of multiple types of cancer (45-47), as well as cancer cell growth $(48,49)$. Similarly, PAK4 plays a major role in the oncogenic processes of different cancers. The overexpression of PAK4 has been shown to promote the proliferation of HCT116 colon cancer cells (50) and MDA-MB-231 breast cancer cells (51), as well as the migration and invasion of MDA-MB-231 cells (51), lung cancer cells (52) and ovarian cancer cells (53). In this study, the upregulation of INKA 2 by the p53 tumour suppressor protein may have suppressed the oncogenic functions of PAK4 by inhibiting the phosphorylation of its substrates. In particular, INKA2 
Table II. Mass spectrometry results.

\begin{tabular}{|c|c|c|c|c|c|c|c|c|c|c|}
\hline $\begin{array}{l}\text { Gene } \\
\text { symbol }\end{array}$ & $\begin{array}{c}\text { Accession } \\
\text { no. }\end{array}$ & Description & $\begin{array}{l}\text { Number of } \\
\text { unique } \\
\text { peptides }\end{array}$ & $\begin{array}{l}\text { Mascot } \\
\text { score }\end{array}$ & $\begin{array}{l}\text { Sequest } \\
\text { HT score }\end{array}$ & $\begin{array}{c}\text { INKA2 } \\
\text { rep1 }\end{array}$ & $\begin{array}{c}\text { INKA2 } \\
\text { rep2 }\end{array}$ & $\begin{array}{c}\text { MOCK } \\
\text { rep1 }\end{array}$ & $\begin{array}{c}\text { MOCK } \\
\text { rep2 }\end{array}$ & Ratio \\
\hline FAM212B & Q9NTI7 & $\begin{array}{l}\text { PAK4-inhibitor } \\
\text { INKA2 } \\
\text { OS=Homo sapiens } \\
\text { GN=FAM212B } \\
\mathrm{PE}=1 \mathrm{SV}=1\end{array}$ & 30 & 6170 & 812.67 & 7076418491 & 7096320012 & 683882 & 1413551 & 6757.18 \\
\hline PAK4 & O96013 & $\begin{array}{l}\text { Serine/threonine- } \\
\text { protein kinase PAK4 } \\
\mathrm{OS}=\text { Homo sapiens } \\
\mathrm{GN}=\mathrm{PAK} 4 \\
\mathrm{PE}=1 \mathrm{SV}=1\end{array}$ & 3 & 108 & 6.12 & 5925410 & 4575458 & 300000 & 390882 & 15.20 \\
\hline HSPA4 & P34932 & $\begin{array}{l}\text { Heat shock } \\
70 \mathrm{kDa} \text { protein } 4 \\
\mathrm{OS}=\text { Homo sapiens } \\
\mathrm{GN}=\text { HSPA } 4 \\
\mathrm{PE}=1 \mathrm{SV}=4\end{array}$ & 7 & 299 & 18.27 & 13257945 & 16261609 & 2184525 & 300000 & 11.88 \\
\hline$Y T H D F 2$ & Q9Y5A9 & $\begin{array}{l}\text { YTH domain- } \\
\text { containing } \\
\text { family protein } 2 \\
\text { OS=Homo sapiens } \\
\text { GN=YTHDF2 } \\
\mathrm{PE}=1 \mathrm{SV}=2\end{array}$ & 2 & 140 & 1.77 & 3488741 & 2239863 & 300000 & 300000 & 9.55 \\
\hline$E M D$ & P50402 & $\begin{array}{l}\text { Emerin } \\
\mathrm{OS}=\text { Homo sapiens } \\
\mathrm{GN}=\mathrm{EMD} \\
\mathrm{PE}=1 \mathrm{SV}=1\end{array}$ & 4 & 139 & 9.45 & 8584906 & 5453183 & 1179338 & 419200 & 8.78 \\
\hline $\begin{array}{l}\text { HSPA1B } \\
\text { HSPA1A }\end{array}$ & P0DMV9 & $\begin{array}{l}\text { Heat shock } \\
70 \mathrm{kDa} \text { protein } 1 \mathrm{~B} \\
\mathrm{OS}=\text { Homo sapiens } \\
\mathrm{GN}=\mathrm{HSPA} 1 \mathrm{~B} \\
\mathrm{PE}=1 \mathrm{SV}=1\end{array}$ & 32 & 4159 & 394.08 & 979983140 & 932523596 & 97516760 & 140257340 & 8.04 \\
\hline HSPA8 & P11142 & $\begin{array}{l}\text { Heat shock cognate } \\
71 \mathrm{kDa} \text { protein } \\
\mathrm{OS}=\text { Homo sapiens } \\
\mathrm{GN}=\mathrm{HSPA} 8 \\
\mathrm{PE}=1 \mathrm{SV}=1\end{array}$ & 28 & 5752 & 513.32 & 866156087 & 770222767 & 103156895 & 135779162 & 6.85 \\
\hline HSPHI & Q92598 & $\begin{array}{l}\text { Heat shock } \\
\text { protein } 105 \mathrm{kDa} \\
\mathrm{OS}=\text { Homo sapiens } \\
\mathrm{GN}=\mathrm{HSPH} 1 \\
\mathrm{PE}=1 \mathrm{SV}=1\end{array}$ & 4 & 160 & 11.23 & 760477 & 2339129 & 184344 & 300000 & 6.40 \\
\hline MYO5A & Q9Y4I1 & $\begin{array}{l}\text { Unconventional } \\
\text { myosin-Va } \\
\text { OS=Homo sapiens } \\
\mathrm{GN}=\mathrm{MYO} 5 \mathrm{~A} \\
\mathrm{PE}=1 \mathrm{SV}=2\end{array}$ & 9 & 266 & 18.12 & 1062376 & 2710392 & 300000 & 300000 & 6.29 \\
\hline CUL3 & Q13618 & $\begin{array}{l}\text { Cullin }-3 \\
\text { OS=Homo sapiens } \\
\text { GN=CUL3 } \\
\text { PE=1 SV=2 }\end{array}$ & 3 & 40 & 0 & 2850262 & 896603 & 300000 & 300000 & 6.24 \\
\hline$A C A D M$ & P11310 & $\begin{array}{l}\text { Medium-chain } \\
\text { specific acyl-CoA } \\
\text { dehydrogenase, } \\
\text { mitochondrial } \\
\text { OS=Homo } \text { sapiens } \\
\text { GN=ACADM } \\
\text { PE=1 SV=1 }\end{array}$ & 1 & 59 & 2.32 & 2910795 & 300000 & 300000 & 300000 & 5.35 \\
\hline
\end{tabular}


A

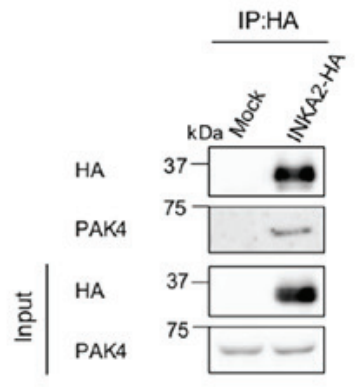

B

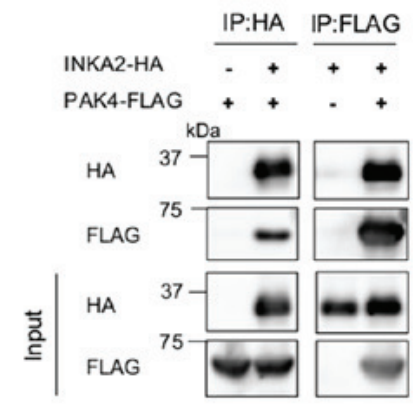

C

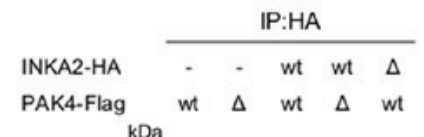

HA

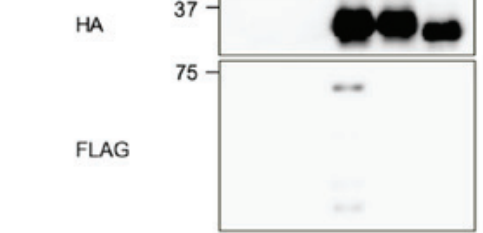

\begin{tabular}{l|l} 
HA & \\
sa & \\
& FLAG
\end{tabular}

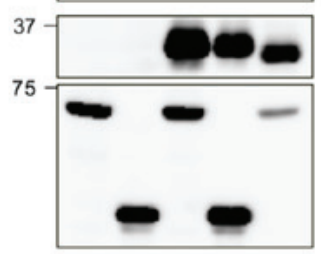

E

$\beta$-catenin

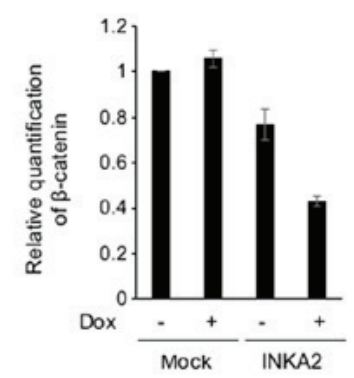

HCT116
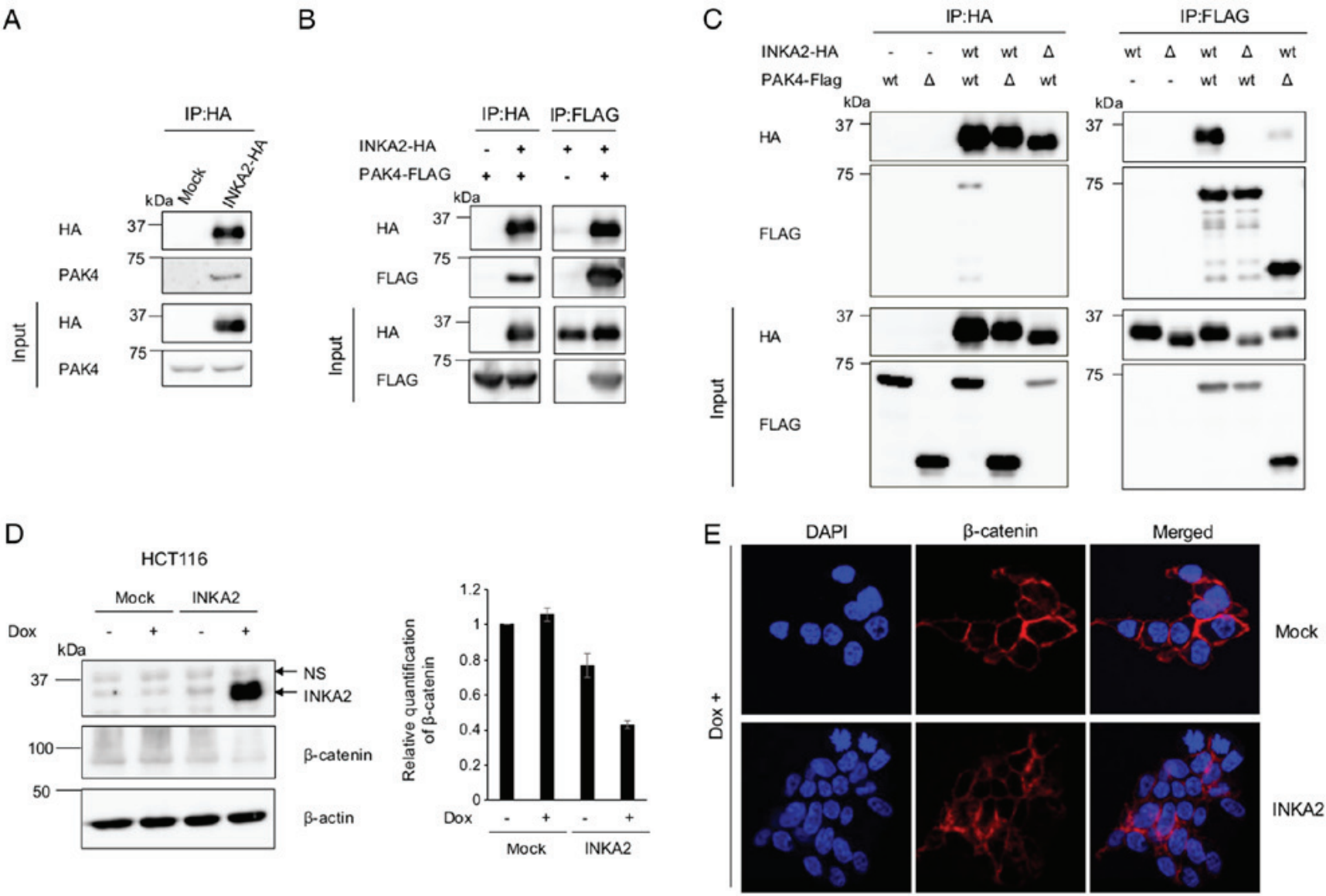

$\mathrm{F}$

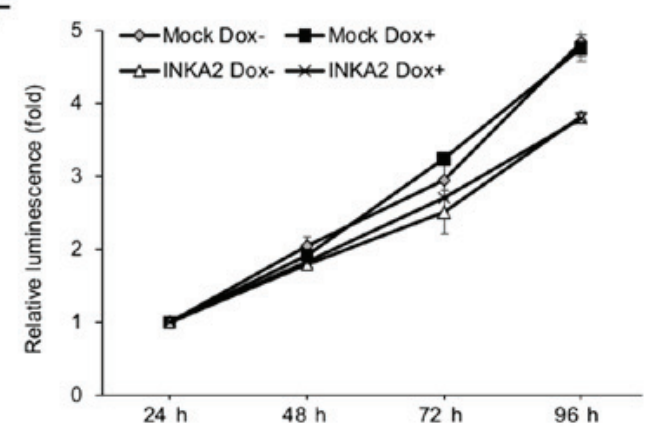

Figure 6. INKA2 binds to the catalytic domain of PAK4 via the iBox domain and downregulates $\beta$-catenin. (A) The pCAGGSnHC empty vector (Mock) or pCAGGSnHC/INKA2 (INKA2-HA) plasmid were transfected into 293T cells. Whole-cell lysates were immunoprecipitated with an anti-HA antibody and blotted with an anti-PAK4 antibody to identify the interaction. (B) The pCAGGSnHC/INKA2 (INKA2-HA) and pCAGGSn3Fc/PAK4 (PAK4-FLAG) plasmids were co-transfected into 293T cells. Whole-cell lysates were immunoprecipitated with an anti-HA or anti-FLAG antibody and blotted with anti-HA and anti-FLAG antibodies. (C) The deletion constructs shown in Fig. 5B were added during the co-transfection depicted in (B). Whole-cell lysates were immunoprecipitated with an anti-HA or anti-FLAG antibody. Wt; wild-type. $\Delta$; deleted versions: INKA2 $\Delta 150-160$ for INKA2, and PAK4 1-325 for PAK4. (D) Whole-cell lysates of the HCT116 cell line stably expressing INKA2 cultured in the presence of Dox were blotted with anti-INKA2 and anti- $\beta$-catenin antibodies. The bar chart represents the quantification of $\beta$-catenin proteins normalised to $\beta$-actin and untreated mock-expressing cells. $\beta$-Actin is shown as a loading control. Error bars are the means $\pm \mathrm{SD}, \mathrm{n}=2$. (E) Immunocytohistochemistry of the stable HCT116 cell line cultured in the presence of Dox. Cells were stained with DAPI (blue) and an antibody against $\beta$-catenin (red). (F) ATP assay performed with the HCT116 cell line stably expressing INKA2 in the presence of Dox. The luminescence of each cell line were normalised to the measurement at 24 -h time-point. Error bars are the means \pm SD, $n=2$. INKA2, inka box actin regulator 2; Dox, doxycycline; PAK4, p21 (RAC1) activated kinase 4.

may inhibit the activation of the Wnt/ $\beta$-catenin signalling pathway by binding to the substrate-docking site of PAK4, thus blocking the phosphorylation of $\beta$-catenin.

In fact, PAK4 is a target of anticancer drugs. Specific PAK4 inhibitors, such as PF-3758309, have been developed as anti-tumour agents. The application of the inhibitor blocks cancer cell growth in vitro and in human xenograft tumour models using nude mice (54). However, the inhibitor failed in clinical trials due to its undesirable pharmacokinetic characteristics (https:/clinicaltrials.gov/ct2/show/NCT00932126). Our finding of the interaction between the INKA 2 iBox and PAK4 catalytic domain may thus contribute to the design of novel PAK4 inhibitors targeting the substrate-docking site of the protein.

The Inka protein family has been studied in developmental biology and has been reported to play an essential role in modulating actin reorganization, cell adhesion, and cell 
migration $(42,44)$. Similarly, the $W n t / \beta$-catenin signalling pathway is known for tissue growth and development (55-57). These data support the hypothesis that INKA2 is a cancer cell growth inhibitor. We hypothesized that INKA2 inhibits cancer cell migration and solidifies the cell junctions or cell polarity that are modified in tumours. Based on our findings regarding the interaction between INKA 2 and PAK4, a reasonable hypothesis is that INKA2 modifies the stability or levels of other PAK4 substrates. We thus anticipate that INKA2 has the potential to diminish cancer cell migration and invasion by inhibiting the kinase function of PAK4. Moreover, PAK4 phosphorylates p53 and is upstream of the p53 signalling pathway $(54,58)$, creating a regulatory feedback loop between p53, INKA2 and PAK4. In conclusion, this study identified INKA2 as a novel downstream target of p53 with cancer cell growth inhibitor functions that inhibits the PAK4 oncogene. These results provide new insight into the role of INKA2 in cancer, and the regulation of PAK4 and its substrates by p53 and INKA2.

\section{Acknowledgements}

The authors are very grateful to Miss Satoyo Oda and Mrs. Akane Sei for providing technical assistance, and to Dr Valaree Yodsurang for her helpful advice (Laboratory of Clinical Genome Sequencing, Department of Computational Biology and Medical Sciences, Graduate School of Frontier Sciences, The University of Tokyo, Tokyo). The authors would like to thank The Cancer Genome Atlas (TCGA) for the publicly available data on their data portal. The authors would also like to thank the Bernstein Lab at the Broad Institute for the human histone mark data from the ENCODE consortium.

\section{Funding}

This study was supported in part by a grant from the Japan Society for the Promotion of Science and the Ministry of Education, Culture, Sports, Science and Technology of Japan to KM and CT, a grant from the Japan Agency for Medical Research and Development to KM and CT, a grant from the Ministry of Health, Labour and Welfare of Japan to KM, and a grant from the Takeda Science Foundation to KM and CT.

\section{Availability of data and materials}

All data generated or analysed during this study are included in this published article.

\section{Authors' contributions}

KM conceived the study. YYL, CT and KM designed the experiments; YL and CT conducted the experiments. KU performed the mass spectrometric analysis. YYL, CT and KM wrote the manuscript, CT and KM proofread the manuscript. All authors have read and approved the final manuscript.

\section{Ethics approval and consent to participate}

Informed consent process allowing for sequencing of DNA from both cancer and normal tissues, and sharing of this information via a controlled-access database that is widely accessible to researchers around the world was obtained by The Cancer Genome Atlas. The animal experiment was approved by the Institutional Review Board of the University of Tokyo (A13-03).

\section{Patient consent for publication}

Not applicable.

\section{Competing interests}

The authors declare that they have no competing interests

\section{References}

1. Vogelstein B, Lane D and Levine AJ: Surfing the p53 network. Nature 408: 307-310, 2000

2. el-Deiry WS, Tokino T, Velculescu VE, Levy DB, Parsons R, Trent JM, Lin D, Mercer WE, Kinzler KW and Vogelstein B: WAF1, a potential mediator of p53 tumor suppression. Cell 75: 817-825, 1993.

3. Bunz F, Dutriaux A, Lengauer C, Waldman T, Zhou S, Brown JP, Sedivy JM, Kinzler KW and Vogelstein B: Requirement for p53 and p21 to sustain G2 arrest after DNA damage. Science 282: 1497-1501, 1998

4. el-Deiry WS, Harper JW, O'Connor PM, Velculescu VE, Canman CE, Jackman J, Pietenpol JA, Burrell M, Hill DE, Wang Y, et al: WAF1/CIP1 is induced in p53-mediated G1 arrest and apoptosis. Cancer Res 54: 1169-1174, 1994.

5. Attardi LD, de Vries A and Jacks T: Activation of the p53-dependent G1 checkpoint response in mouse embryo fibroblasts depends on the specific DNA damage inducer. Oncogene 23: 973-980, 2004.

6. He G, Siddik ZH, Huang Z, Wang R, Koomen J, Kobayashi R, Khokhar AR and Kuang J: Induction of $\mathrm{p} 21$ by $\mathrm{p} 53$ following DNA damage inhibits both Cdk4 and Cdk2 activities. Oncogene 24: 2929-2943, 2005

7. Garner E and Raj K: Protective mechanisms of p53-p21-pRb proteins against DNA damage-induced cell death. Cell Cycle 7: 277-282, 2008

8. Xu J and Morris GF: p53-mediated regulation of proliferating cell nuclear antigen expression in cells exposed to ionizing radiation. Mol Cell Biol 19: 12-20, 1999.

9. Grombacher T, Eichhorn U and Kaina B: p53 is involved in regulation of the DNA repair gene O6-methylguanine-DNA methyltransferase (MGMT) by DNA damaging agents. Oncogene 17: 845-851, 1998.

10. Laptenko $\mathrm{O}$ and Prives C: Transcriptional regulation by p53: One protein, many possibilities. Cell Death Differ 13: 951-961, 2006.

11. Tanikawa C, Zhang YZ, Yamamoto R, Tsuda Y, Tanaka M, Funauchi Y, Mori J, Imoto S, Yamaguchi R, Nakamura Y, et al: The transcriptional landscape of p53 signalling pathway. EBioMedicine 20: 109-119, 2017.

12. Miyamoto T, Tanikawa C, Yodsurang V, Zhang YZ, Imoto S, Yamaguchi R, Miyano S, Nakagawa $\mathrm{H}$ and Matsuda $\mathrm{K}$ : Identification of a p53-repressed gene module in breast cancer cells. Oncotarget 8: 55821-55836, 2017.

13. Koguchi T, Tanikawa C, Mori J, Kojima Y and Matsuda K: Regulation of myo-inositol biosynthesis by p53-ISYNA1 pathway. Int J Oncol 48: 2415-2424, 2016.

14. Yodsurang V, Tanikawa C, Miyamoto T, Lo PHY, Hirata M and Matsuda K: Identification of a novel p53 target, COL17A1, that inhibits breast cancer cell migration and invasion. Oncotarget 8: 55790-55803, 2017.

15. Chèneby $\mathrm{J}$, Gheorghe $\mathrm{M}$, Artufel $\mathrm{M}$, Mathelier $\mathrm{A}$ and Ballester $\mathrm{B}$ : ReMap 2018: An updated atlas of regulatory regions from an integrative analysis of DNA-binding ChIP-seq experiments. Nucleic Acids Res 46: D267-D275, 2018.

16. Zhou KR, Liu S, Sun WJ, Zheng LL, Zhou H, Yang JH and Qu LH: ChIPBase v2.0: Decoding transcriptional regulatory networks of non-coding RNAs and protein-coding genes from ChIP-seq data. Nucleic Acids Res 45: D43-D50, 2017.

17. KhanA,Fornes O,Stigliani A, GheorgheM,Castro-MondragonJA, van der Lee R, Bessy A, Chèneby J, Kulkarni SR, Tan G, et al: JASPAR 2018: Update of the open-access database of transcription factor binding profiles and its web framework. Nucleic Acids Res 46: D260-D266, 2018. 
18. Wei CL, Wu Q, Vega VB, Chiu KP, Ng P, Zhang T, Shahab A, Yong HC, Fu Y, Weng Z, et al: A global map of p53 transcription-factor binding sites in the human genome. Cell 124 207-219, 2006

19. el-Deiry WS, Tokino T, Waldman T, Oliner JD, Velculescu VE, Burrell M, Hill DE, Healy E, Rees JL, Hamilton SR, et al: Topological control of p21WAF1/CIP1 expression in normal and neoplastic tissues. Cancer Res 55: 2910-2919, 1995.

20. Schneider CA, Rasband WS and Eliceiri KW: NIH Image to ImageJ: 25 years of image analysis. Nat Methods 9: 671-675, 2012

21. Takahashi Y, Tanikawa C, Miyamoto T, Hirata M, Wang G, Ueda K, Komatsu T and Matsuda K: Regulation of tubular recycling endosome biogenesis by the p53-MICALL1 pathway. Int J Oncol 51: 724-736, 2017.

22. Cerami E, Gao J, Dogrusoz U, Gross BE, Sumer SO, Aksoy BA Jacobsen A, Byrne CJ, Heuer ML, Larsson E, et al: The cBio cancer genomics portal: An open platform for exploring multidimensional cancer genomics data. Cancer Discov 2: 401-404, 2012.

23. Gao J, Aksoy BA, Dogrusoz U, Dresdner G, Gross B, Sumer SO, Sun Y, Jacobsen A, Sinha R, Larsson E, et al: Integrative analysis of complex cancer genomics and clinical profiles using the cBioPortal. Sci Signal 6: pl1, 2013.

24. Huang WY, Hsu SD, Huang HY, Sun YM, Chou CH, Weng SL and Huang HD: MethHC: A database of DNA methylation and gene expression in human cancer. Nucleic Acids Res 43 D856-D861, 2015.

25. Baxter EW and Milner J: p53 Regulates LIF expression in human medulloblastoma cells. J Neurooncol 97: 373-382, 2010.

26. Budanov AV, Shoshani T, Faerman A, Zelin E, Kamer I, Kalinski H, Gorodin S, Fishman A, Chajut A, Einat P, et al: Identification of a novel stress-responsive gene Hi95 involved in regulation of cell viability. Oncogene 21: 6017-6031, 2002.

27. Quintens R, Verreet T, Janssen A, Neefs M, Leysen L, Michaux A Verslegers M, Samari N, Pani G, Verheyde J, et al: Identification of novel radiation-induced p53-dependent transcripts extensively regulated during mouse brain development. Biol Open 4: 331-344, 2015

28. Nakano K and Vousden KH: PUMA, a novel proapoptotic gene, is induced by p53. Mol Cell 7: 683-694, 2001

29. Endo Y, Fujita T, Tamura K, Tsuruga $H$ and Nojima H: Structure and chromosomal assignment of the human cyclin $\mathrm{G}$ gene. Genomics 38: 92-95, 1996.

30. Zhang Y, Shin SJ, Liu D, Ivanova E, Foerster F, Ying H, Zheng H, Xiao Y, Chen Z, Protopopov A, et al: ZNF365 promotes stability of fragile sites and telomeres. Cancer Discov 3: 798-811, 2013.

31. Sung YH, Kim HJ, Devkota S, Roh J, Lee J, Rhee K, Bahk YY and Lee HW: Pierce1, a novel p53 target gene contributing to the ultraviolet-induced DNA damage response. Cancer Res 70 : 10454-10463, 2010.

32. Kawase T, Ohki R, Shibata T, Tsutsumi S, Kamimura N, Inazawa J, Ohta $\mathrm{T}$, Ichikawa $\mathrm{H}$, Aburatani $\mathrm{H}$, Tashiro $\mathrm{F}$, et al: $\mathrm{PH}$ domain-only protein PHLDA3 is a p53-regulated repressor of Akt. Cell 136: 535-550, 2009.

33. Hsieh WJ, Hsieh SC, Chen CC and Wang FF: Human DDA3 is an oncoprotein down-regulated by p53 and DNA damage. Biochem Biophys Res Commun 369: 567-572, 2008

34. Osada M, Park HL, Park MJ, Liu JW, Wu G, Trink B and Sidransky D: A p53-type response element in the GDF15 promoter confers high specificity for p53 activation. Biochem Biophys Res Commun 354: 913-918, 2007.

35. Tanikawa C, Furukawa Y, Yoshida N, Arakawa H, Nakamura Y and Matsuda K: XEDAR as a putative colorectal tumor suppressor that mediates p53-regulated anoikis pathway. Oncogene 28 3081-3092, 2009.

36. Consortium EP; ENCODE Project Consortium: An integrated encyclopedia of DNA elements in the human genome. Nature 489: 57-74, 2012.

37. Kent WJ, Sugnet CW, Furey TS, Roskin KM, Pringle TH, Zahler AM and Haussler D: The human genome browser at UCSC. Genome Res 12: 996-1006, 2002

38. Baskaran Y, Ang KC, Anekal PV, Chan WL, Grimes JM, Manser E and Robinson RC: An in cellulo-derived structure of PAK4 in complex with its inhibitor Inka1. Nat Commun 6: 8681, 2015.

39. Ha BH, Davis MJ, Chen C, Lou HJ, Gao J, Zhang R, Krauthammer M, Halaban R, Schlessinger J, Turk BE, et al: Type II p21-activated kinases (PAKs) are regulated by an autoinhibitory pseudosubstrate. Proc Natl Acad Sci USA 109: 16107-16112, 2012
40. Wang W, Lim L, Baskaran Y, Manser E and Song J: NMR binding and crystal structure reveal that intrinsically-unstructured regulatory domain auto-inhibits PAK4 by a mechanism different from that of PAK1. Biochem Biophys Res Commun 438: 169-174, 2013.

41. Li Y, Shao Y, Tong Y, Shen T, Zhang J, Li Y, Gu H and Li F: Nucleo-cytoplasmic shuttling of PAK4 modulates $\beta$-catenin intracellular translocation and signaling. Biochim Biophys Acta 1823: 465-475, 2012.

42. Luo T, Xu Y, Hoffman TL, Zhang T, Schilling T and Sargent TD: Inca: A novel p21-activated kinase-associated protein required for cranial neural crest development. Development 134: 1279-1289, 2007

43. Reid BS, Sargent TD and Williams T: Generation and characterization of a novel neural crest marker allele, Inka1-LacZ, reveals a role for Inka1 in mouse neural tube closure. Dev Dyn 239: 1188-1196, 2010.

44. Iwasaki Y, Yumoto T and Sakakibara S: Expression profiles of inka2 in the murine nervous system. Gene Expr Patterns 19: 83-97, 2015

45. Debebe A, Medina V, Chen CY, Mahajan IM, Jia C, Fu D, He L, Zeng N, Stiles BW, Chen CL, et al: Wnt/ $\beta$-catenin activation and macrophage induction during liver cancer development following steatosis. Oncogene 36: 6020-6029, 2017.

46. Lee K and A Piazza G: The interaction between the Wnt/ $\beta$-catenin signaling cascade and PKG activation in cancer. J Biomed Res 31 189-196, 2017.

47. Chong PS, Zhou J, Chooi JY, Chan ZL, Toh SH, Tan TZ, Wee S, Gunaratne J, Zeng Q and Chng WJ: Non-canonical activation of beta-catenin by PRL-3 phosphatase in acute myeloid leukemia. Oncogene 38: 1508-1519, 2018

48. Sinnberg T, Menzel M, Ewerth D, Sauer B, Schwarz M, Schaller M, Garbe C and Schittek B: $\beta$-Catenin signaling increases during melanoma progression and promotes tumor cell survival and chemoresistance. PLoS One 6: e23429, 2011.

49. Yang CM, Ji S, Li Y, Fu LY, Jiang T and Meng FD: $\beta$-Catenin promotes cell proliferation, migration, and invasion but induces apoptosis in renal cell carcinoma. OncoTargets Ther 10: 711-724, 2017.

50. Zhang X, Zhang X, Li Y, Shao Y, Xiao J, Zhu G and Li F: PAK4 regulates G6PD activity by p53 degradation involving colon cancer cell growth. Cell Death Dis 8: e2820, 2017.

51. He LF, Xu HW, Chen M, Xian ZR, Wen XF, Chen MN, Du CW, Huang WH, Wu JD and Zhang GJ: Activated-PAK4 predicts worse prognosis in breast cancer and promotes tumorigenesis through activation of $\mathrm{PI} 3 \mathrm{~K} / \mathrm{AKT}$ signaling. Oncotarget 8: 17573-17585, 2017.

52. Cai S, Ye Z, Wang X, Pan Y, Weng Y, Lao S, Wei H and Li L: Overexpression of $\mathrm{P} 21$-activated kinase 4 is associated with poor prognosis in non-small cell lung cancer and promotes migration and invasion. J Exp Clin Cancer Res 34: 48, 2015.

53. Siu MK, Chan HY, Kong DS, Wong ES, Wong OG, Ngan HY, Tam KF, Zhang H, Li Z, Chan QK, et al: p21-activated kinase 4 regulates ovarian cancer cell proliferation, migration, and invasion and contributes to poor prognosis in patients. Proc Natl Acad Sci USA 107: 18622-18627, 2010.

54. Murray BW, Guo C, Piraino J, Westwick JK, Zhang C, Lamerdin J, Dagostino E, Knighton D, Loi CM, Zager M, et al: Small-molecule p21-activated kinase inhibitor PF-3758309 is a potent inhibitor of oncogenic signaling and tumor growth. Proc Natl Acad Sci USA 107: 9446-9451, 2010.

55 . Fujimura N: WNT/ $\beta$-catenin signaling in vertebrate eye development. Front Cell Dev Biol 4: 138, 2016.

56. Duan $\mathrm{P}$ and Bonewald LF: The role of the wnt/ $\beta$-catenin signaling pathway in formation and maintenance of bone and teeth. Int $\mathrm{J}$ Biochem Cell Biol 77: 23-29, 2016.

57. Tamamura Y, Otani T, Kanatani N, Koyama E, Kitagaki J, Komori T, Yamada Y, Costantini F, Wakisaka S, Pacifici M, et al: Developmental regulation of Wnt/beta-catenin signals is required for growth plate assembly, cartilage integrity, and endochondral ossification. J Biol Chem 280: 19185-19195, 2005.

58. Xu HT, Lai WL, Liu HF, Wong LL, Ng IO and Ching YP: PAK4 phosphorylates p53 at serine 215 to promote liver cancer metastasis. Cancer Res 76: 5732-5742, 2016.

This work is licensed under a Creative Commons Attribution-NonCommercial-NoDerivatives 4.0 International (CC BY-NC-ND 4.0) License. 